[119]

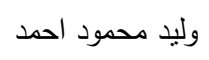

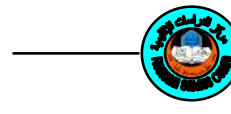
تطورات الأمن الأورويسي

وليد محمود احمد مدرس / قسم الدراسات السياسية والإستراتيجية مركز الدراسات الإقليمية / جامعة الموصل

مستخلص البحث

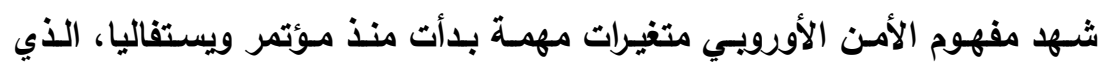

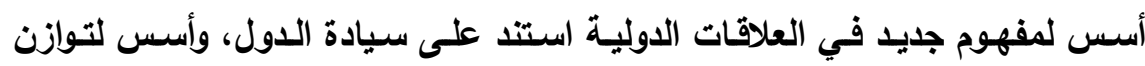

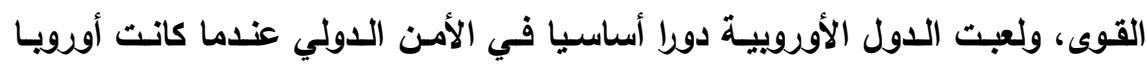

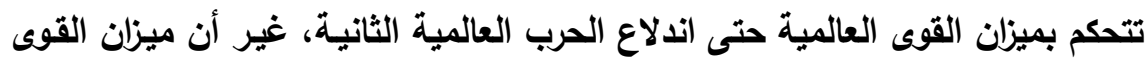

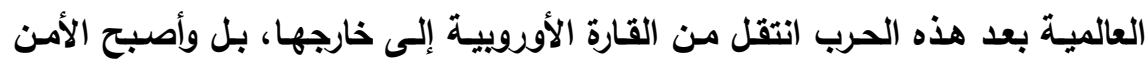

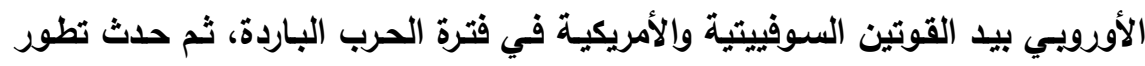

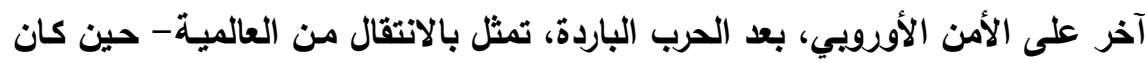

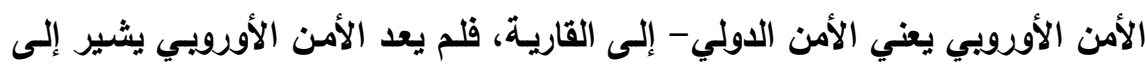

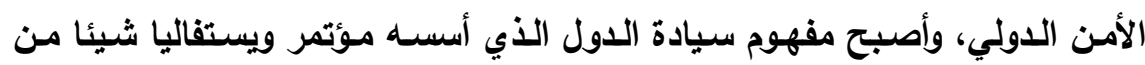

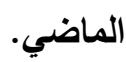
ثمة مفارقة في الفكر الأوروبي المتعلق بهذه المسالة، فبعد الحرب العالمية الأولى المقل

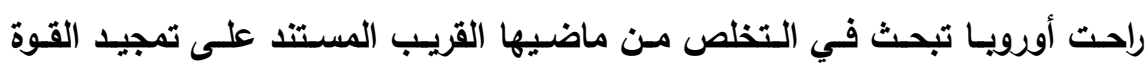

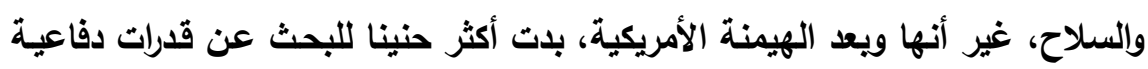
تؤكد فيها وجودها في أفق القرن الحادي والعشرين. 


\section{مقدمة}

كان مفهوم الأمن الجماعي الأوروبي ولا يزال هدفا نسعى إليه غالبية

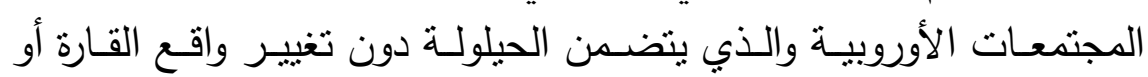

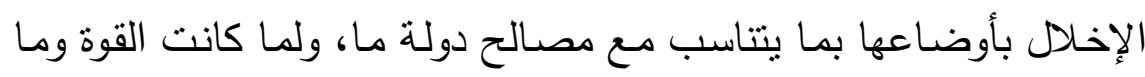

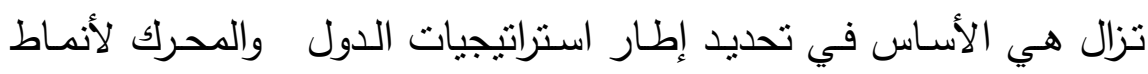

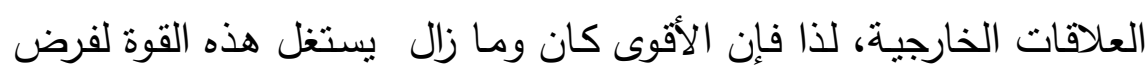

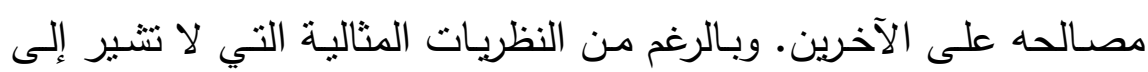

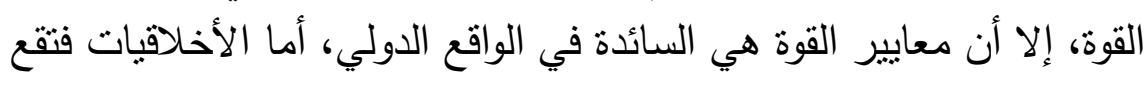

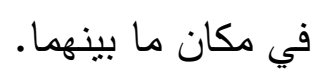

لم تكن القارة الأوروبية قد شهدت على على مر تاريخها ازدهارا وأمنا وحرية

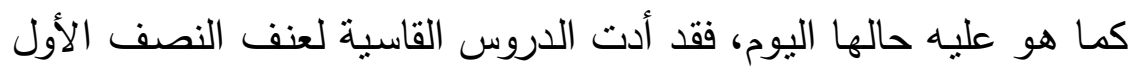

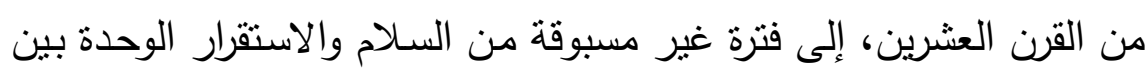

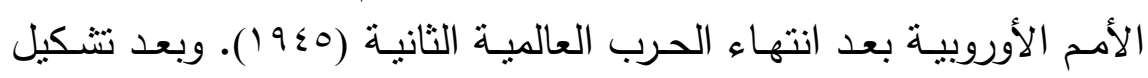

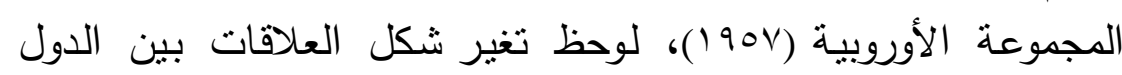

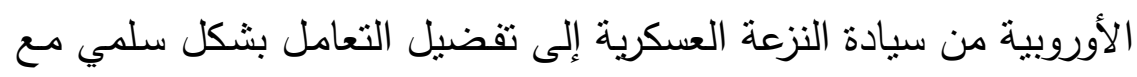

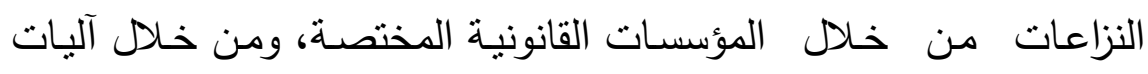

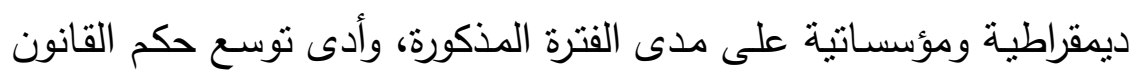

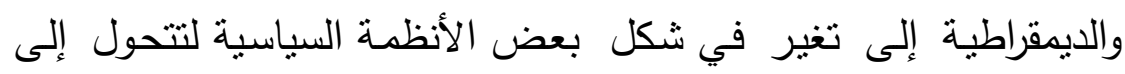

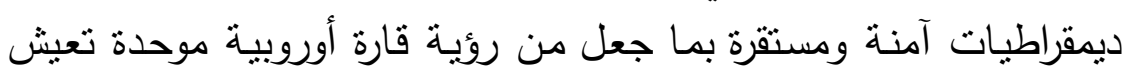
بسلام، حقيقة لا بمكن نكرانها.

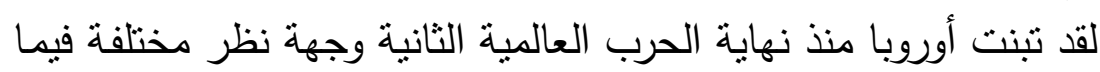

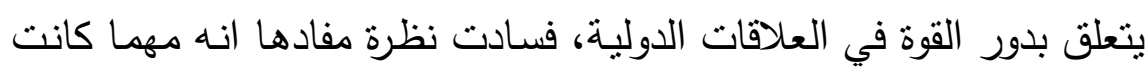

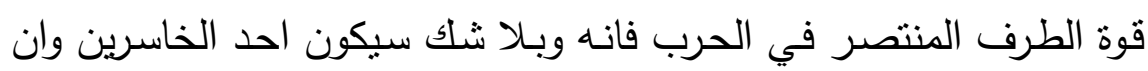
اقل بالمقارنة مـع الطرف المهزوم. كان ذلك على خلفية تجاربها التاريخية، 
وما خلفته الحربان العالميتان الأولى، والثانية من نتائج سلبية مادية ومعنوية ألقت بظلالها على شعوب القارة الأوروبية.

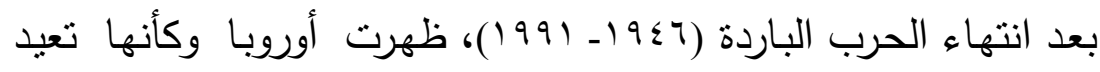

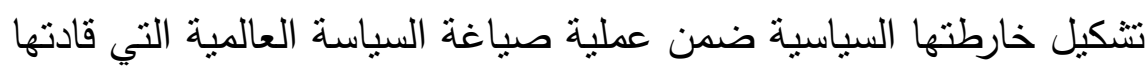

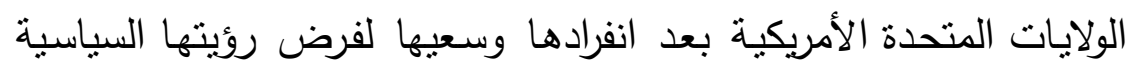

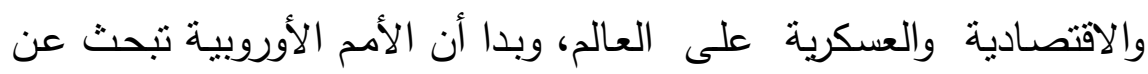

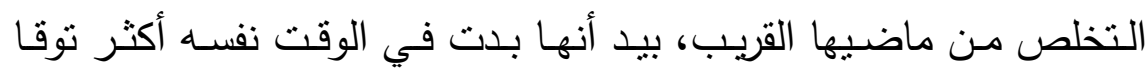

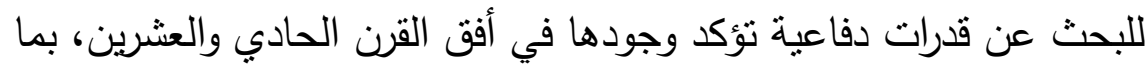

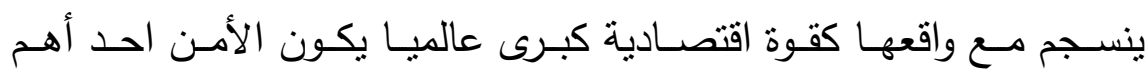
ضروراتها. بناء على ما تقدم، سيحاول البحث أن يتعرض لمسالة الأمن الأوروبي عبر مراحل تطورها.

\section{مفهوم الأمن الأورويي}

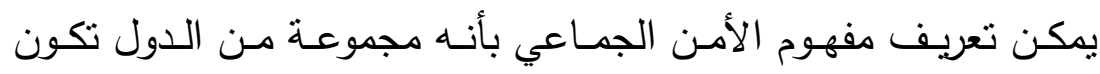

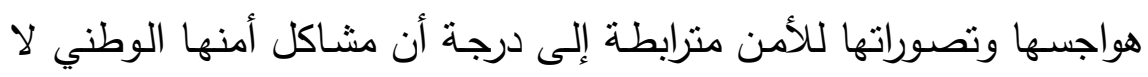

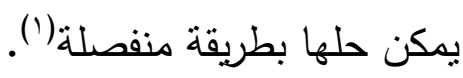

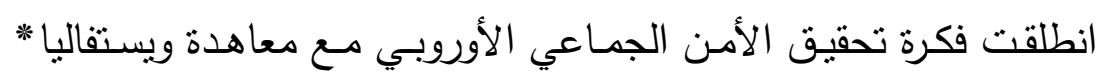

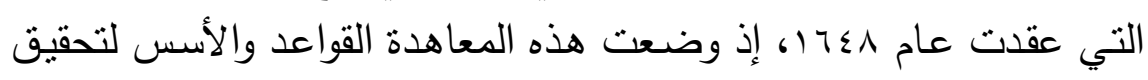

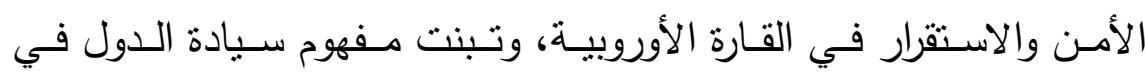

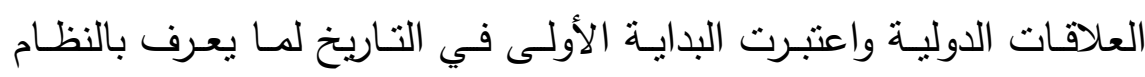

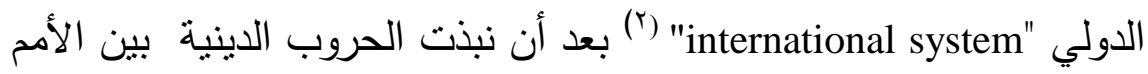

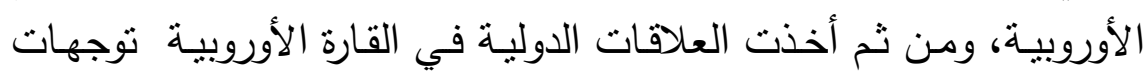

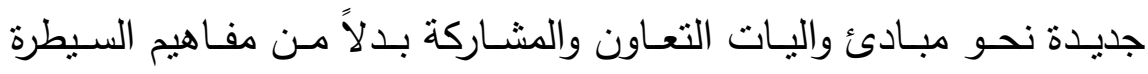

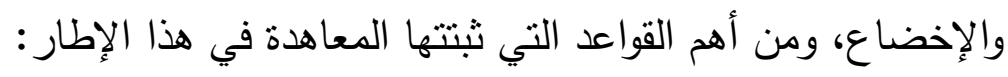


اـ دعوة الأمم الأوروبية للمشاورات عند حدوث إثكاليات والعمل على إيجاد

$$
\begin{aligned}
& \text { حلول لها على أساس المصالح المشتركة. } \\
& \text { r- الإقرار بمبدأ المساواة بين الأمم الأوروبية. }
\end{aligned}
$$

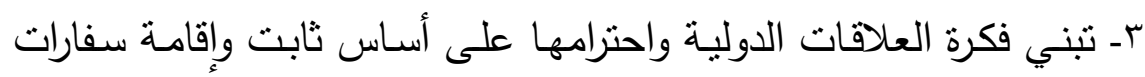
دائمة على أراضي الدول الأوروبية.

ــ اعتماد مبدأ التوازن الدولي كأساس للحفاظ على الأمن السلم في القارة

هـ فرض سيادة الدولة في الداخل وفي علاقاتها الخارجية.

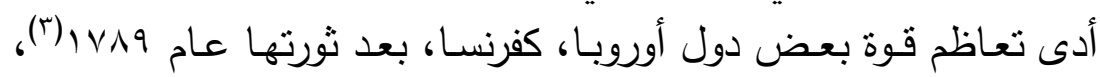

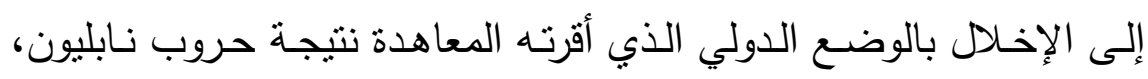

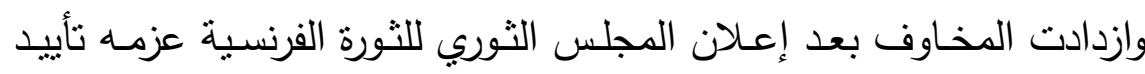

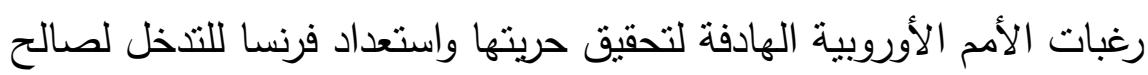

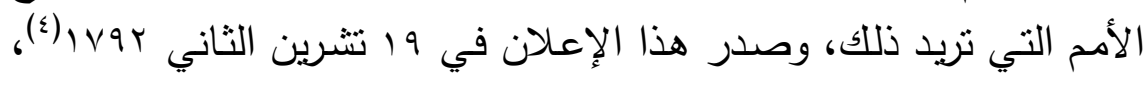

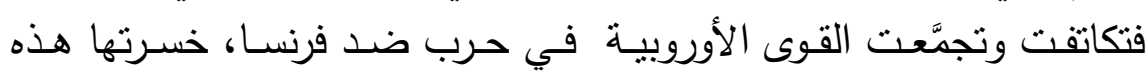

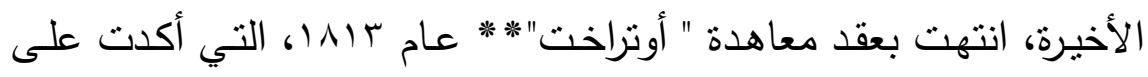
مبادئ معاهدة "ويستفاليا" بإعادة تتظيم أوروبا.

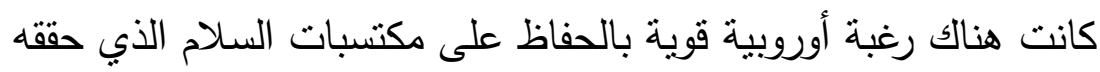

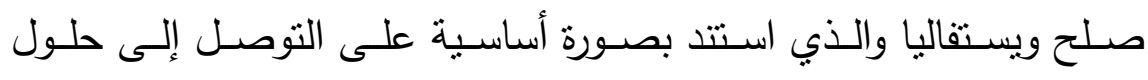

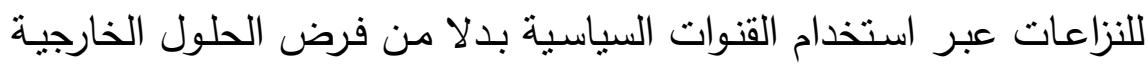

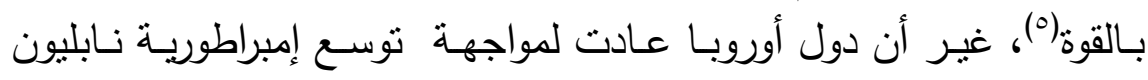

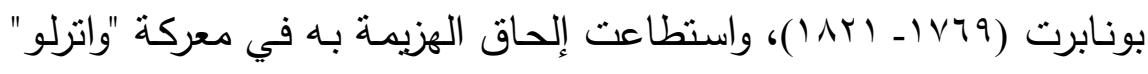

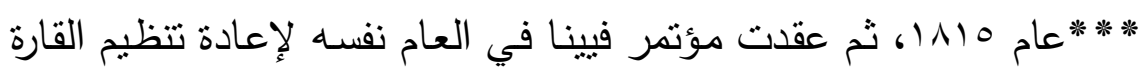
الأوروبية من جديد (T). 


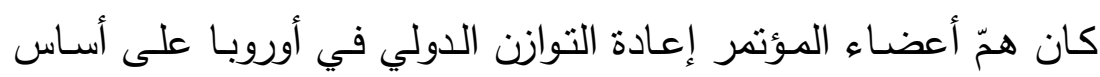

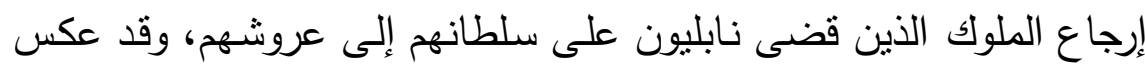
هذا المؤتمر إرادة الإطراف المنتصرة في الحرب ضد نابليون، وهي إنكلترا

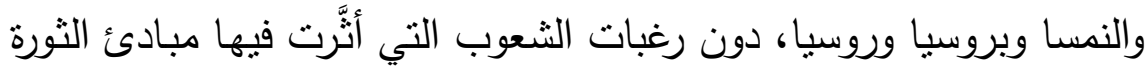

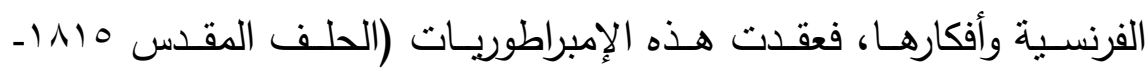

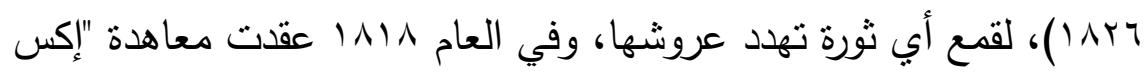

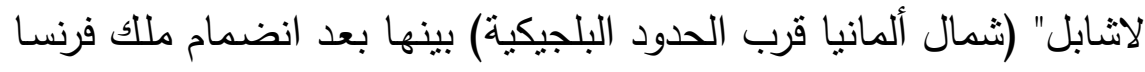

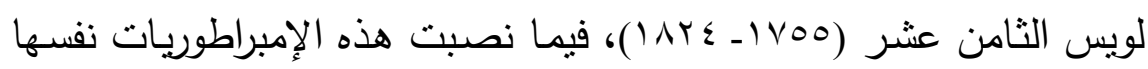

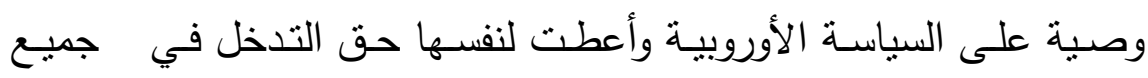
النزاعات الأوروبية والدفاع عن الأنظمة الملكية في أي مكان تراه مهدَّداً،

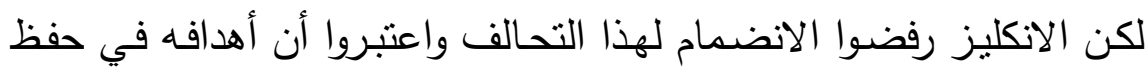

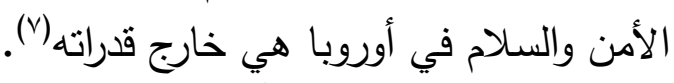

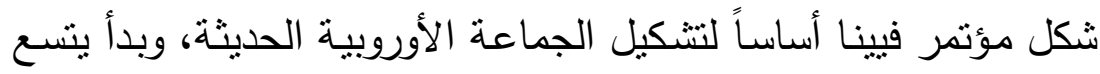

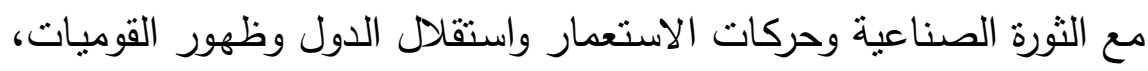

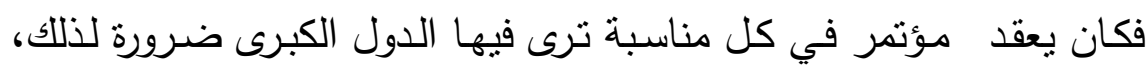

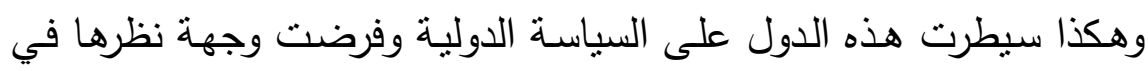

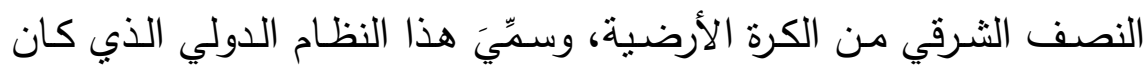

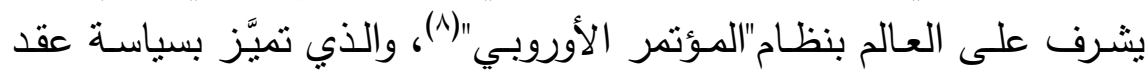

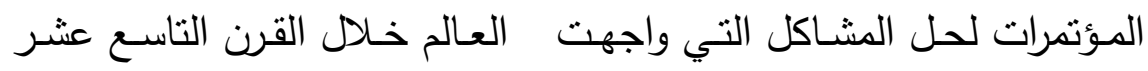

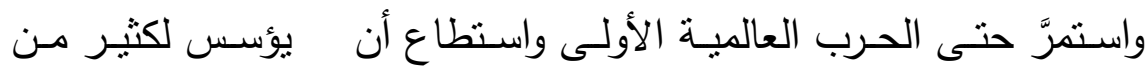
المعاهدات التي ما زالت في الكثير منها قائمة حتى اليوم، كاتفاقيات جنيف

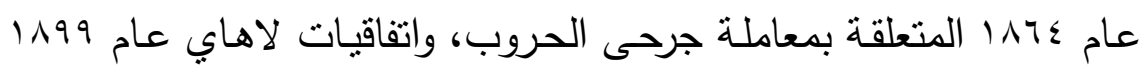
و V.9. الخاصة بقواعد الحرب وتسوية النزاعات بالطرق السلمية. الأمن الأورويي قبل الحرب العالمية الأولى 
مـع مطلـع القـرن العثـرين، اسـتقر في العلاقـات الدوليـة مفهوم (الأمـن

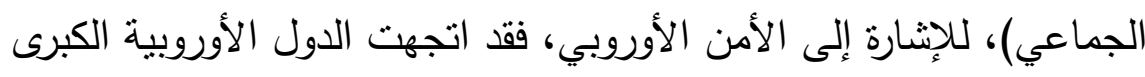

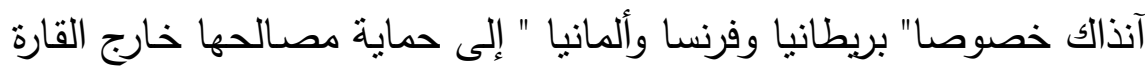

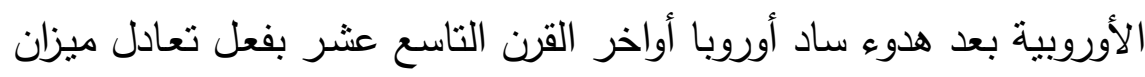
القوى، ولم تستطع بعض الحوادث مثثل الحرب بين العثمانيين واليونـانيين

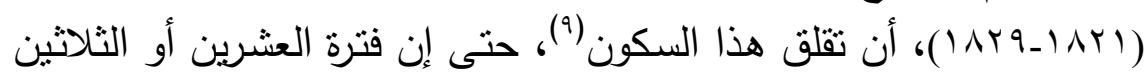

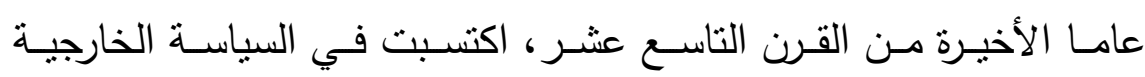

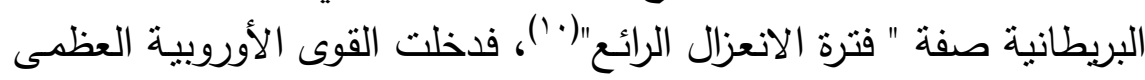
ما عرف بعصر السياسة العالمية (').

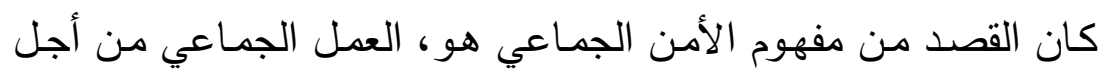

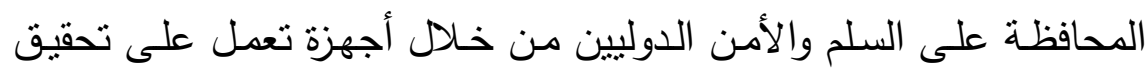
هذا الهدف. وبرغم تعدد التعريفات التي تنتاول هذا المفهوم واختلافها فيما بينها، إلا انه يمكن تحديد مجموعة من النقاط الأساسية التي تلتقي حولها

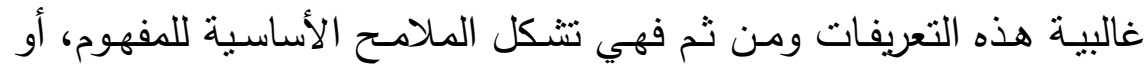

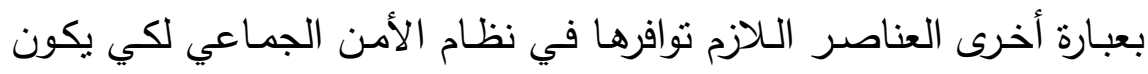

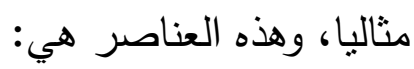

\section{(أ) تحريم استخدام القوة في العلاقات بين الدول}

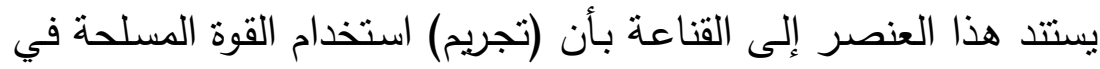

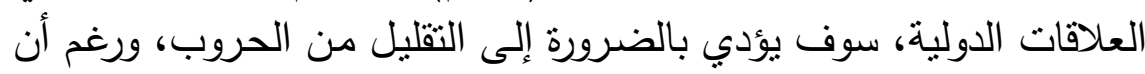

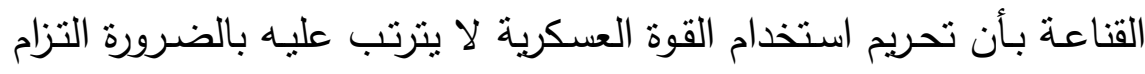

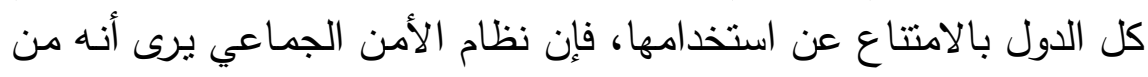

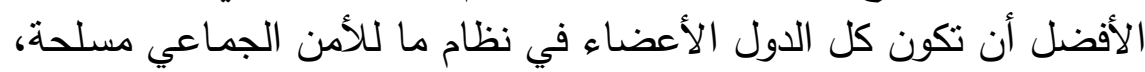

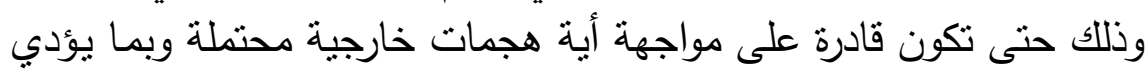

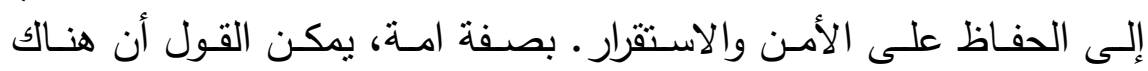


اعتراف وقبول عام بين الدول بأهية تحريم استخدام القوة، إلا أن كل الدول

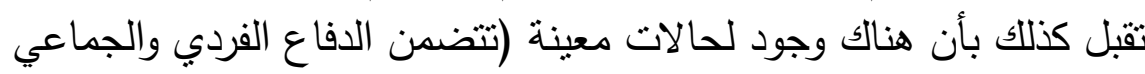

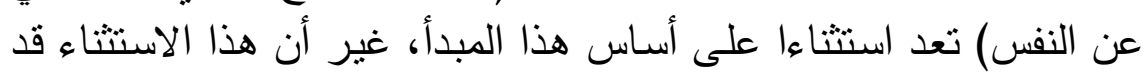

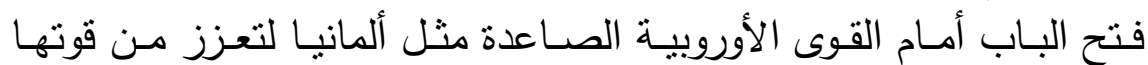

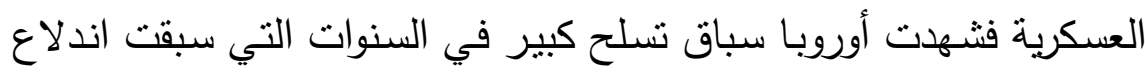

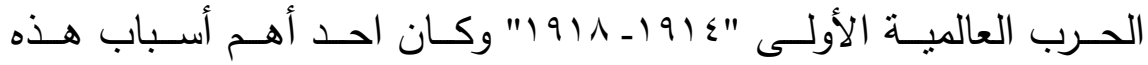

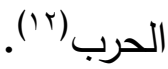

(ب) الضمان الجماعي للأمن

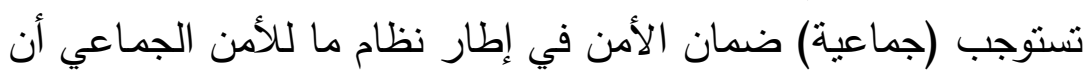

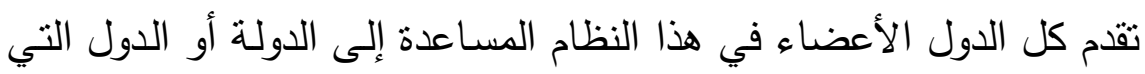

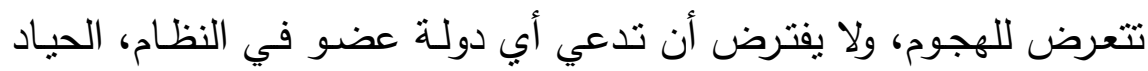

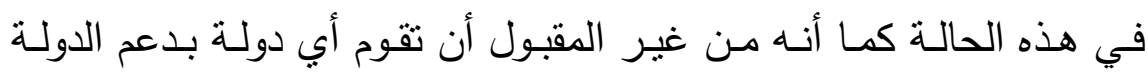

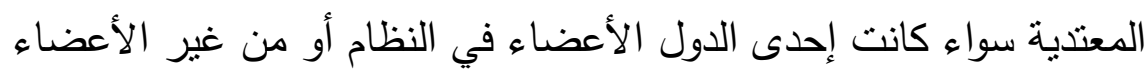

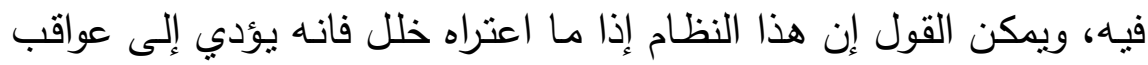

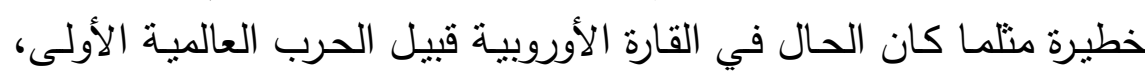

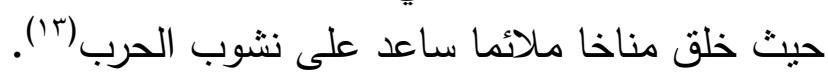

\section{(ج) استخدام القوة كرادع وكعقاب في الوقت ذاته}

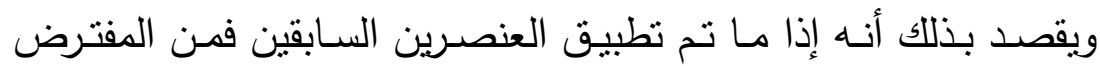

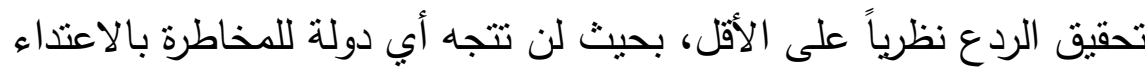

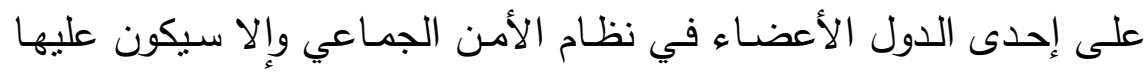

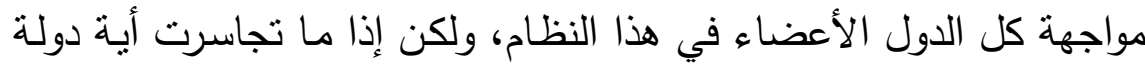

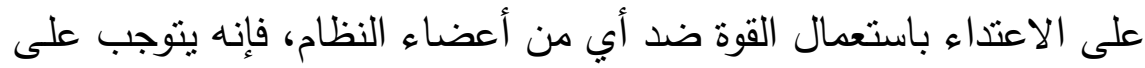
القوات المشتركة لكل الدول الأخرى أن تتصدى لهذاء الأنداء الاعتداء. وفي الحقيقة 
إن القـوة كـرادع أسـهمت كثيـرا فـي إضـعاف الدبلوماسـية وسـيادة الـروح العسكرية (1) ().

\section{(د) (د) تلقائية العمل الجماعي}

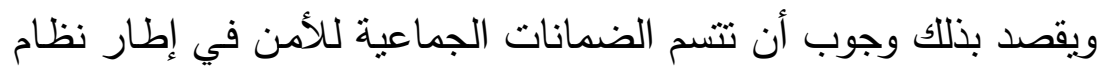

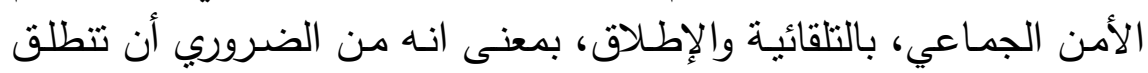

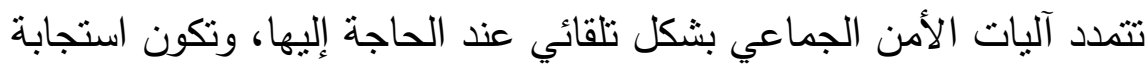

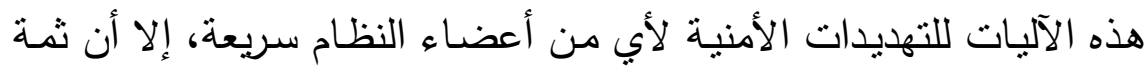

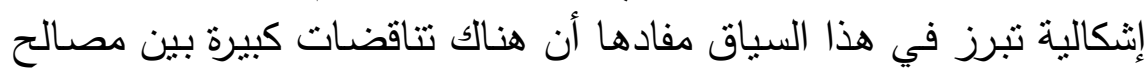

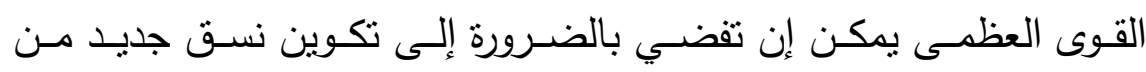

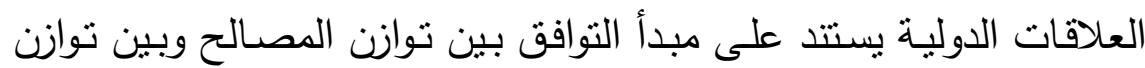

(ه) أولوية عضوية نظام الأمن الجماعي على ما عداها من تحالفات

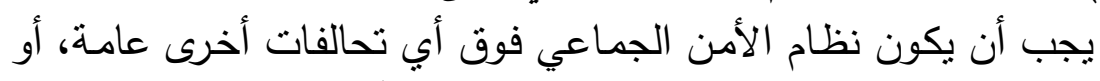

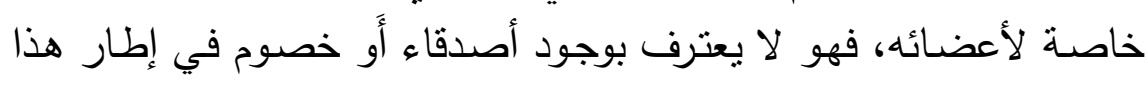

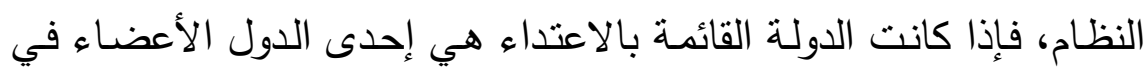

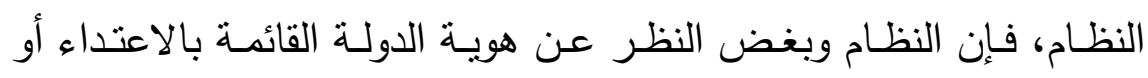

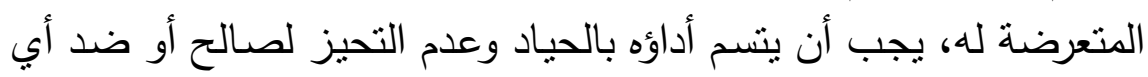

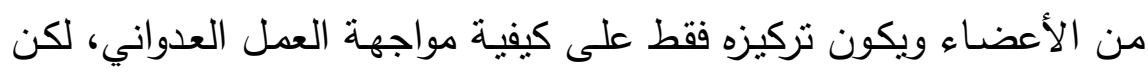

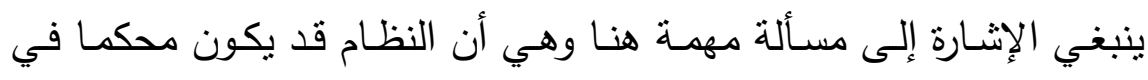

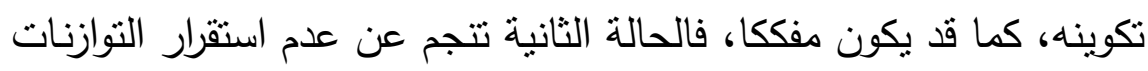

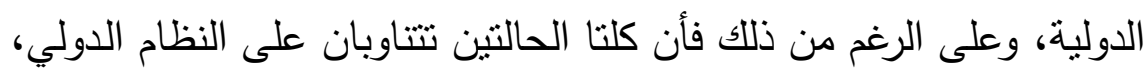

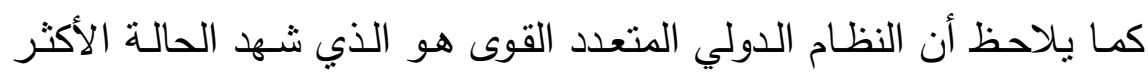
استقرارا في مجال التتافس الدولي والدصالح الدولية(1). 
(ر) التوافق على معنى الاعتداء أو العدوان

يفترض هذا العنصـر أن تقبـل كل الدول الأعضـاء في نظسام الأمسن

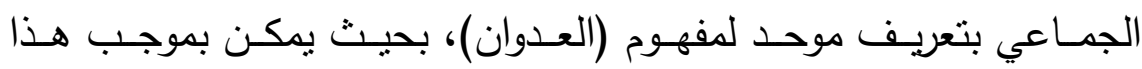

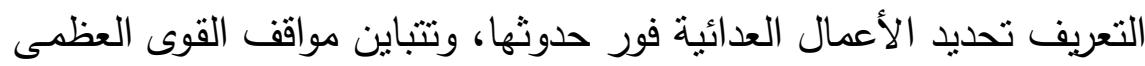

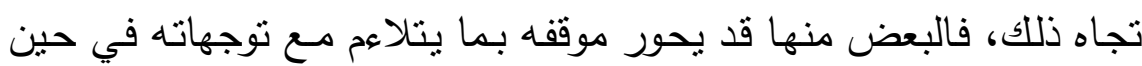
تفضل دول أخرى عدم المواجهة ('v') (س) ديمومة وعمومية النظام يجب أن ينسم نظام الأمن الجماعي بالديمومة، وان وان يكون مجرداً وعاماً

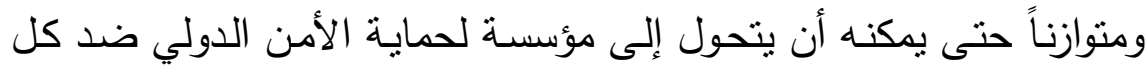

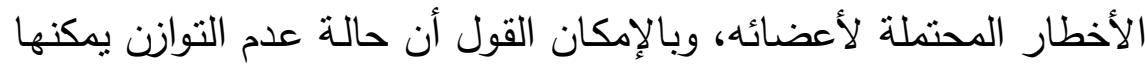

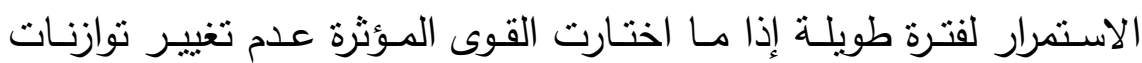

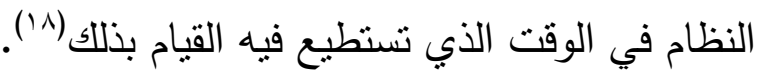

\section{عصبة الأمم (919 19 - 19 19) ومفهوم الأمن الجماعي}

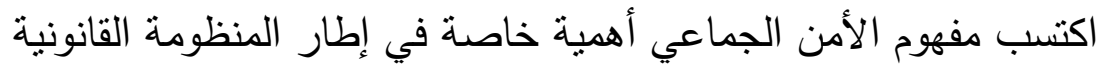

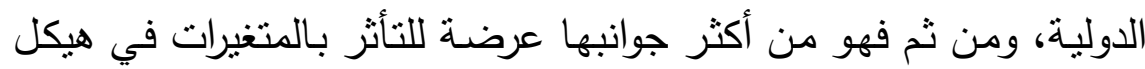
النظام السياسي الدولي وهذا ما ظهر واضحا في النطبيقات المختلفة للمفهوم والتي اختلفت وتطورت مع المتغيرات في شكل النظام العالمي.

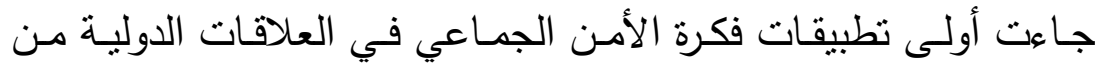

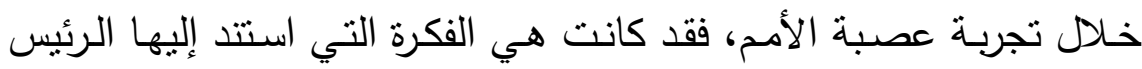

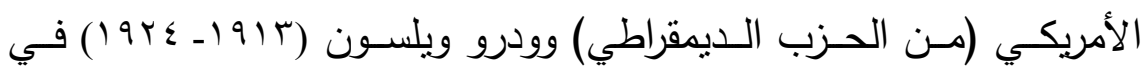

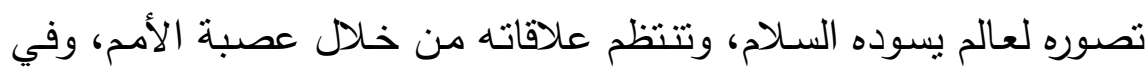

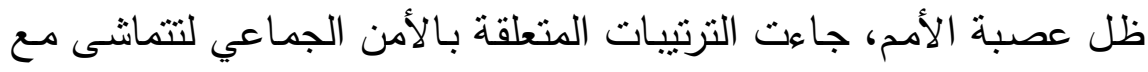

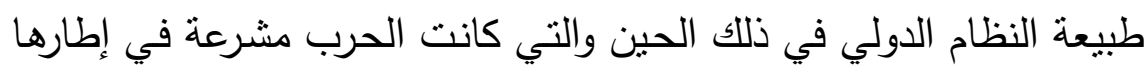


باعتبارها إحدى طرق إدارة العلاقات الدولية، غير إن عهد العصبة لم ينص

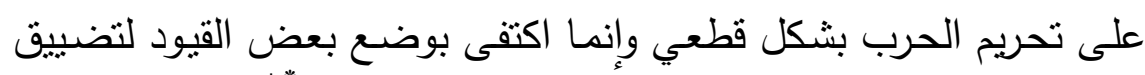

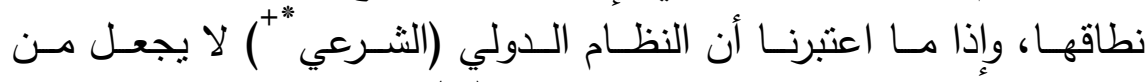

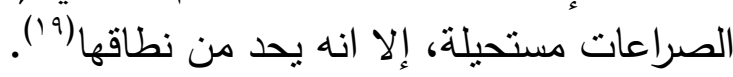

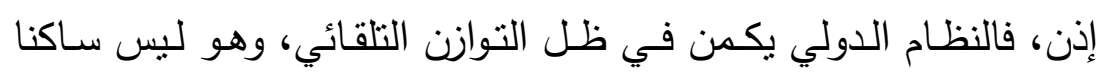

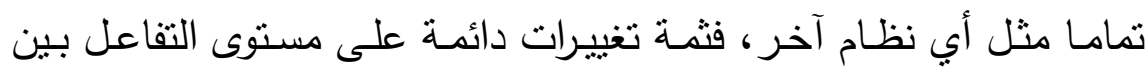

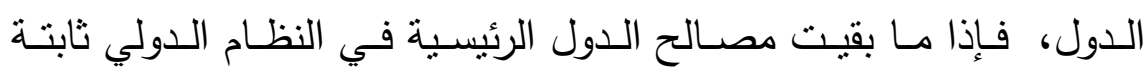

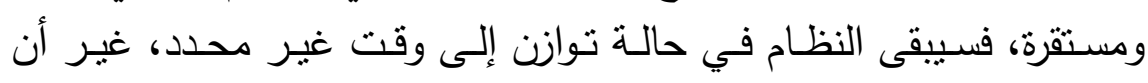

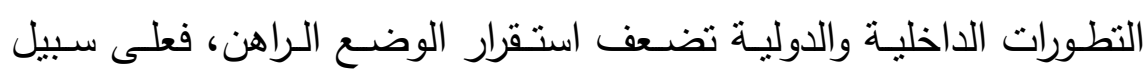

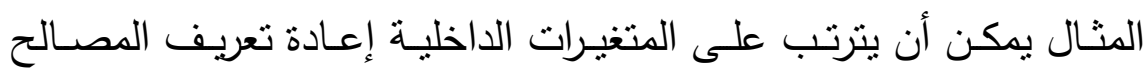

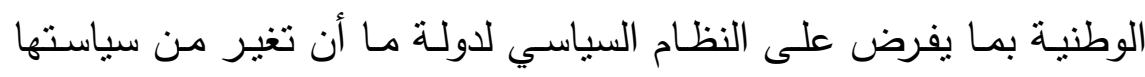
الخارجية والتي قد تصطدم بمصالح دولة أخرى(·r).

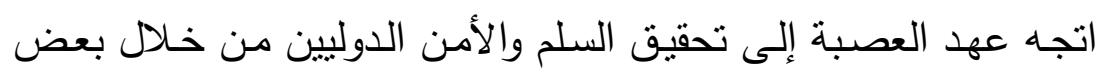

$$
\begin{aligned}
& \text { الوسائل التي يمكن إجمالها في اتجاهين: } \\
& \text { (أ) العمل على منع الحروب }
\end{aligned}
$$

يكون ذلك من خلال مجموعة من الآليات مثل حل المنازعات بالوسائل السلمية والحد من التسلح، فضلا عن ربط المعاهدات الدولية بعهد العصبة.

\section{(ب) إجراءات مواجهة العدوان}

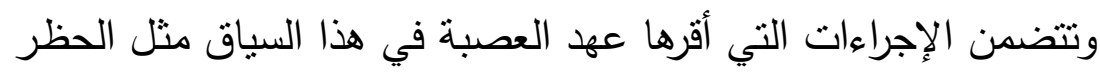

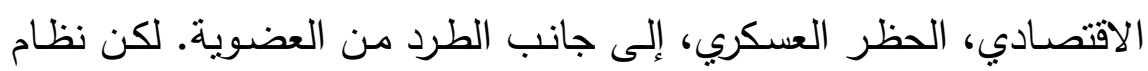

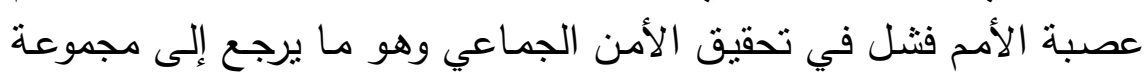

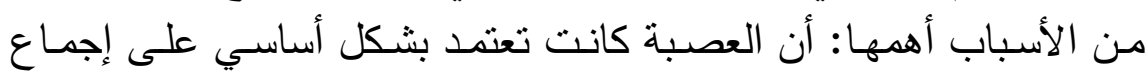

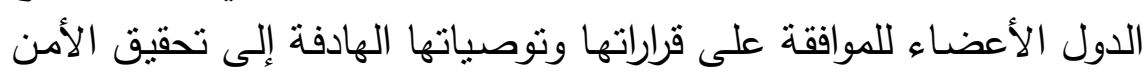


الجمـاعي وهو مـا لم يمكن تحقيقهـ بسبب التوترات السياسية بين الدول

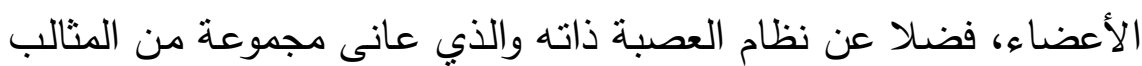

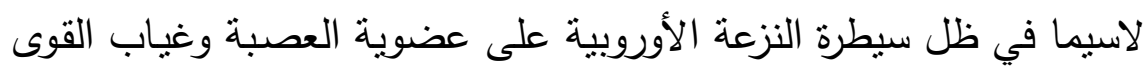

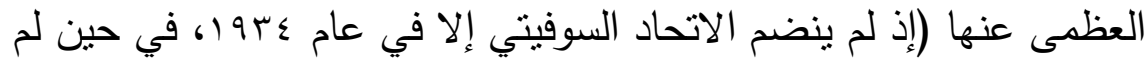

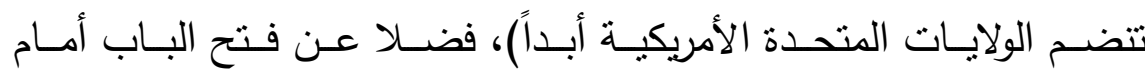

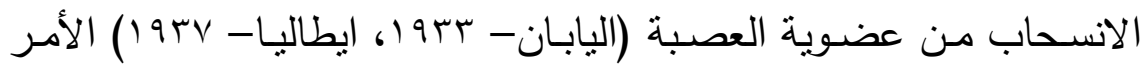

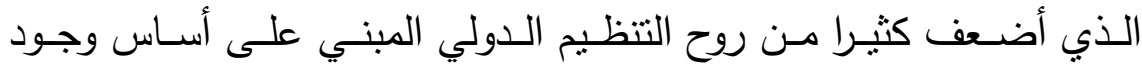

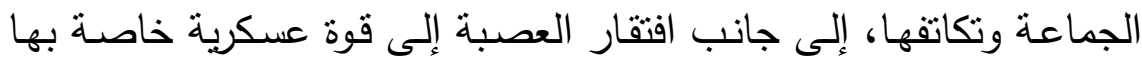

وفثلها في مواجهة إعادة النسلح الألماني (بارئ.

\section{الأمن الجماعي بعد الحرب العالمية الثانية}

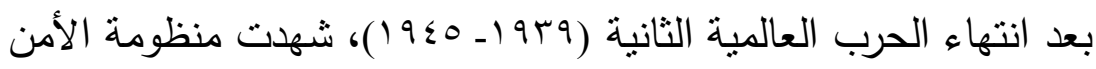

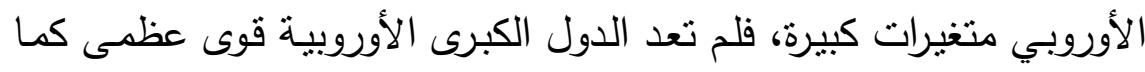

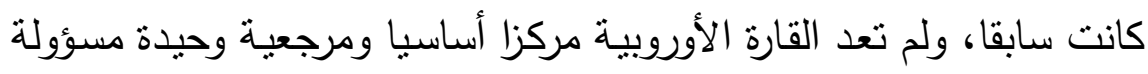

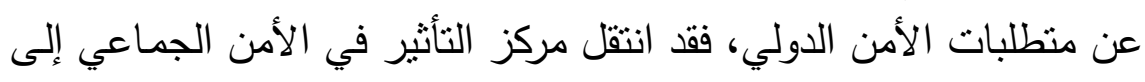

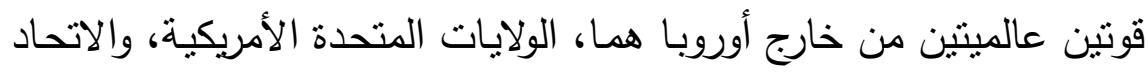

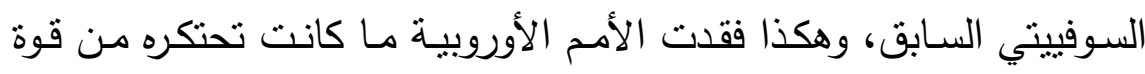

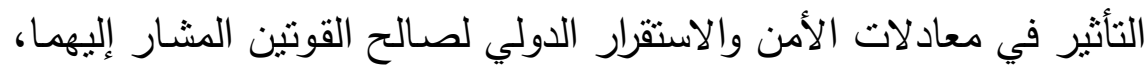

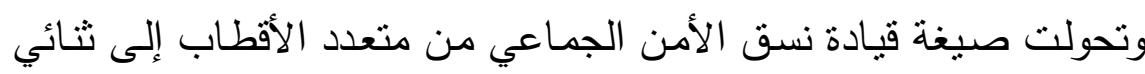

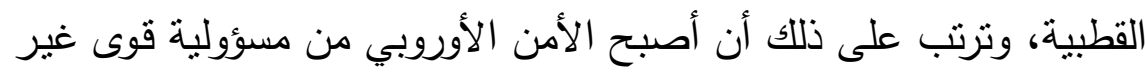

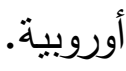

بدأت صياغة نظام الأمن الجماعي في إطار منظمة الأمم المتحدة بعد

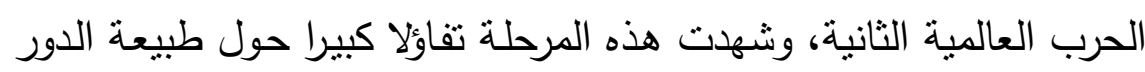

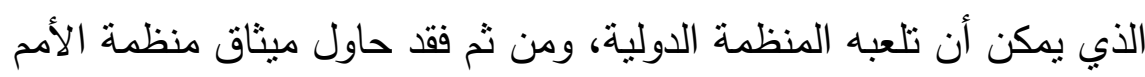
المتحدة أن يضـع تحت تصـرف مجلس الأمسن الدولي - بصفته الجهاز 
المسؤول عن الإدارة المشتركة لنظام الأمن الجماعي الوسائل والإمكانيات

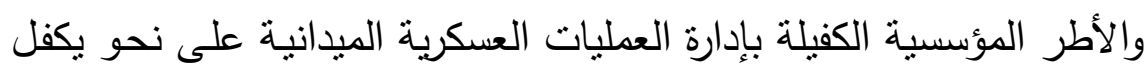

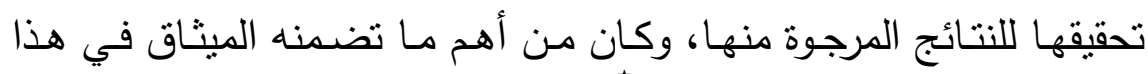

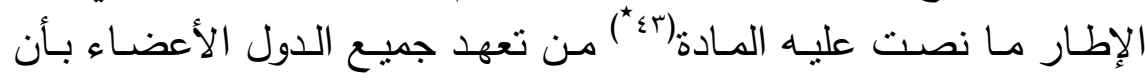

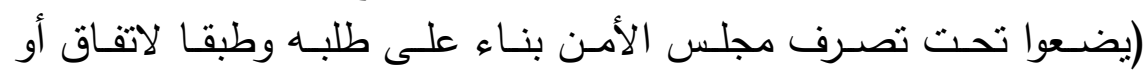

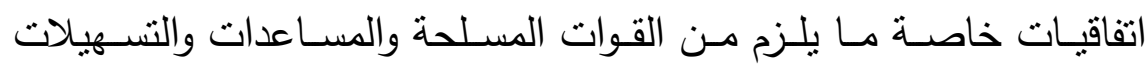

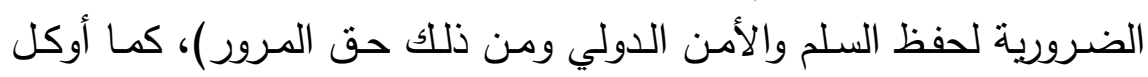

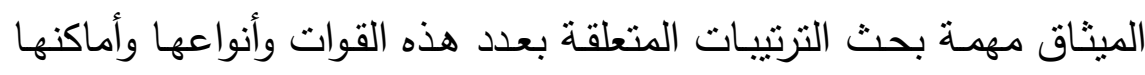

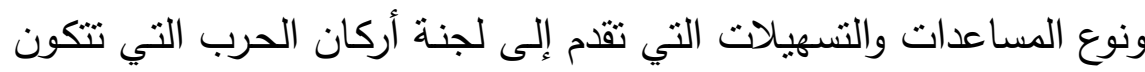

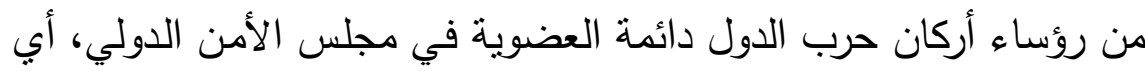

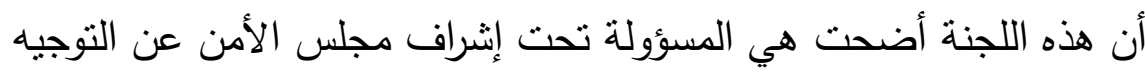

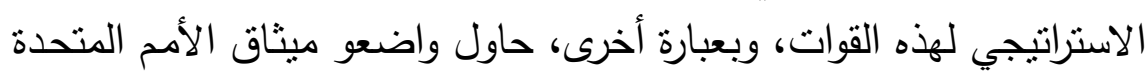

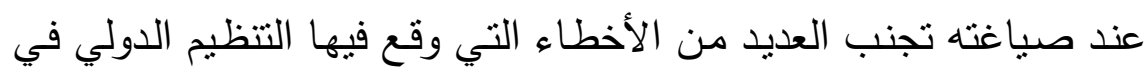

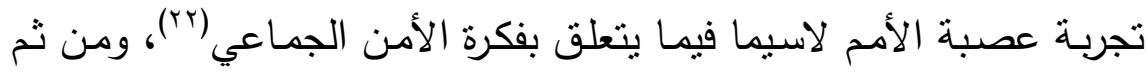

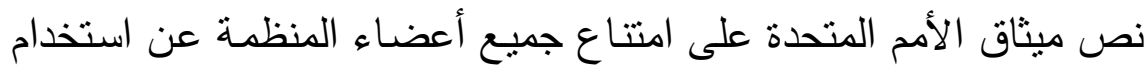

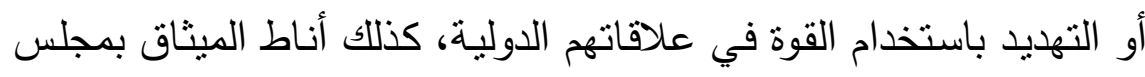

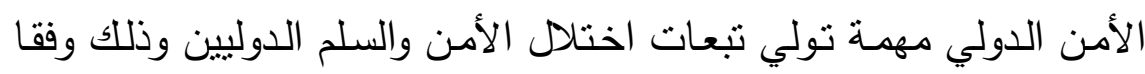

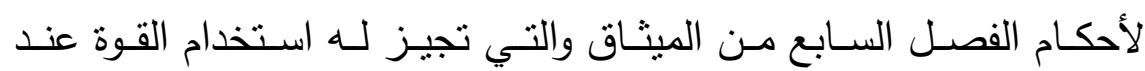

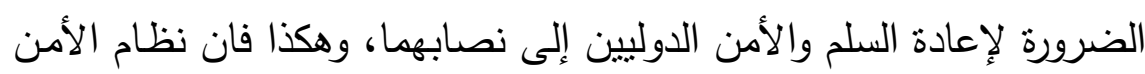
الجماعي في إطار منظمة الأمم المتحدة قد قام على دعامتين أساسيتين،

(أ) حظر استخدام القوة في العلاقات الدولية أو التهديد بها، وبرغم عدم

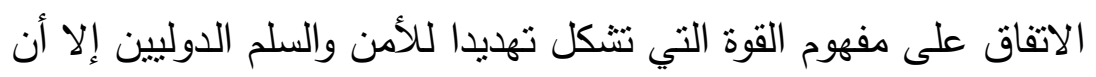

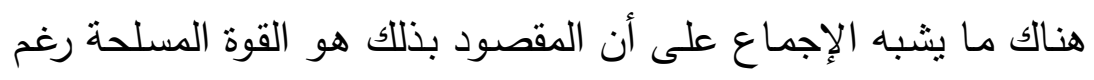

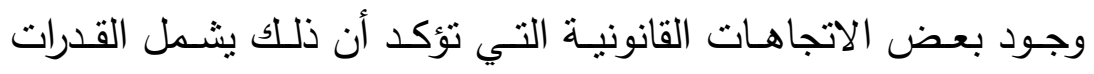




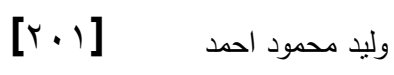
تطورات الأمن الأوروبي

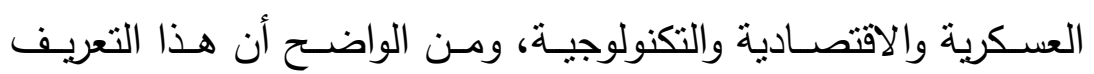

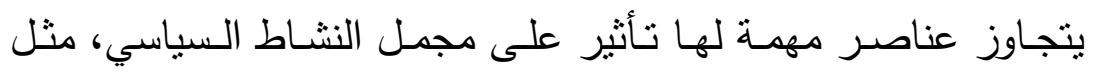

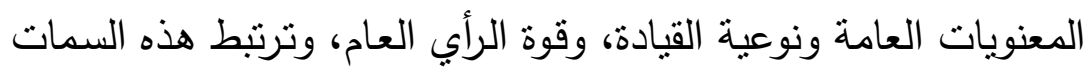

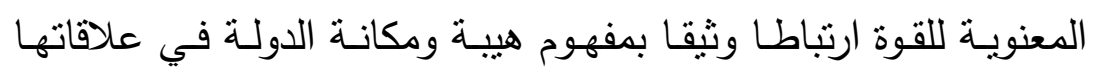

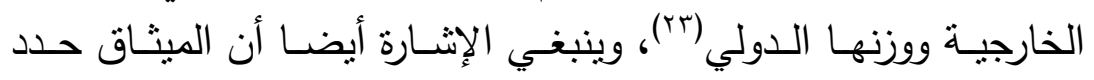

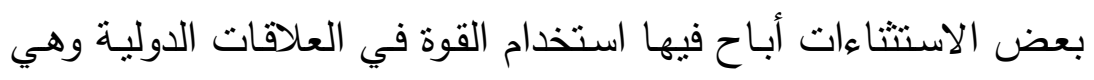

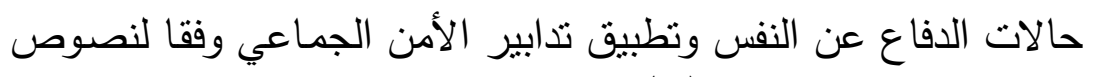

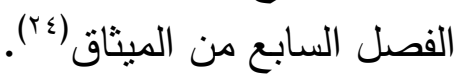

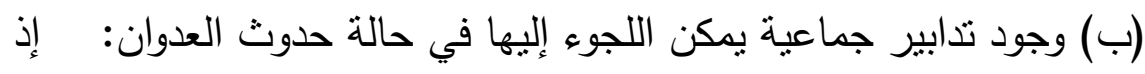

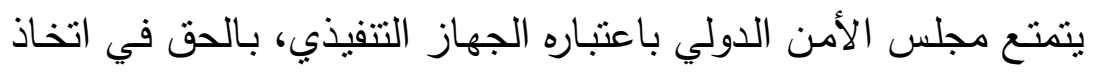

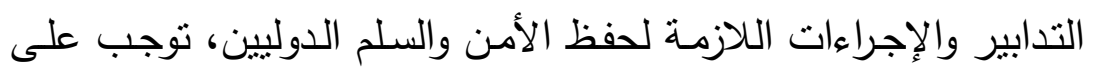

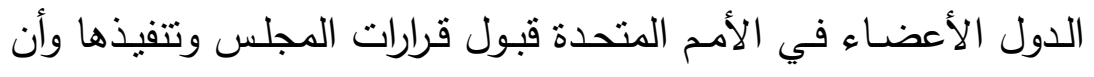

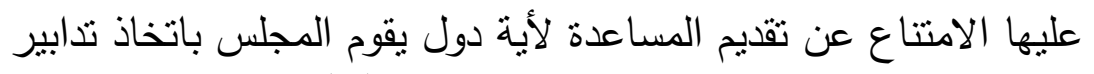

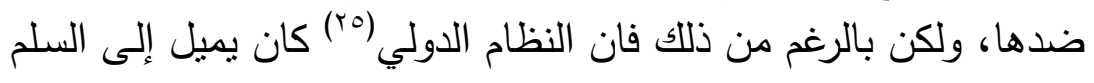

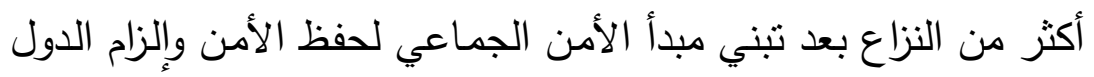

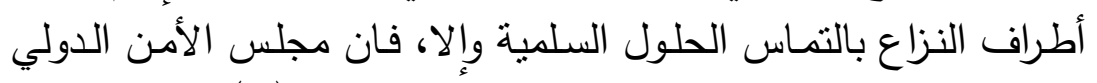

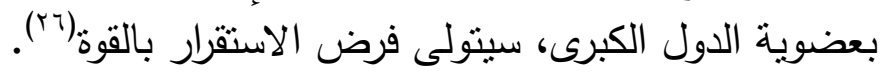

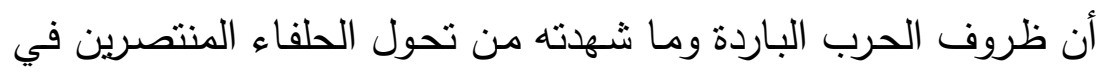

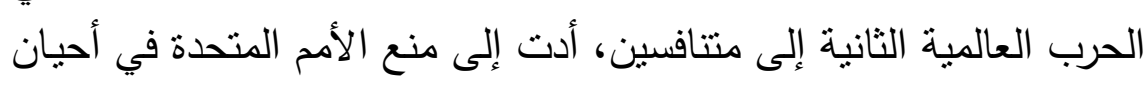

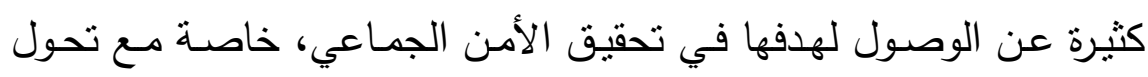

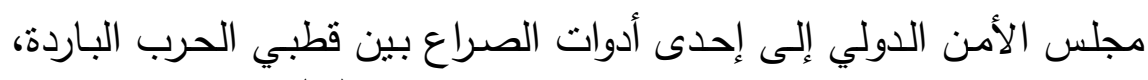

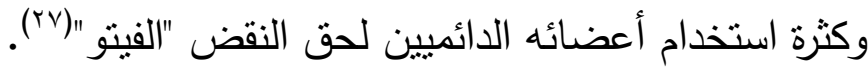

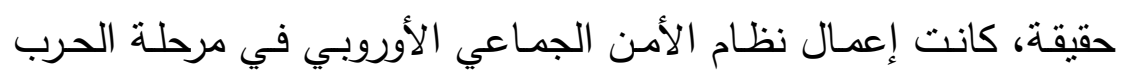

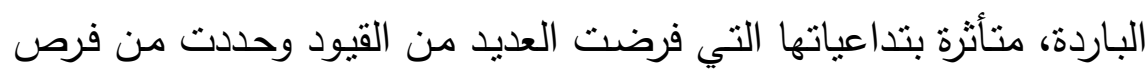

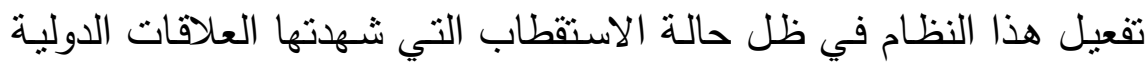


آنذاك، الأمر الذي جعل من الأمن الأوروبي في مرحلة الحرب الباردة رهينا

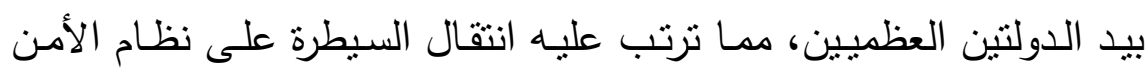

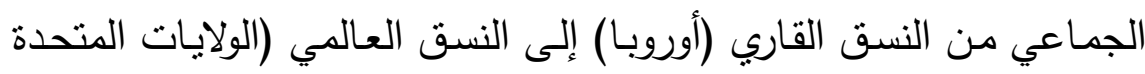

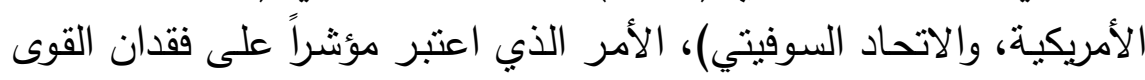

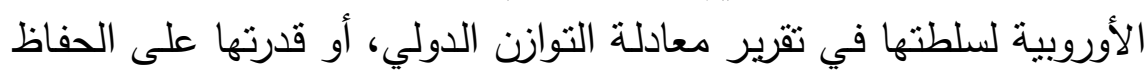

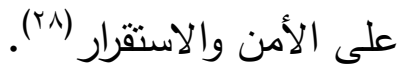

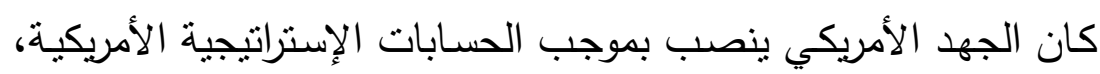

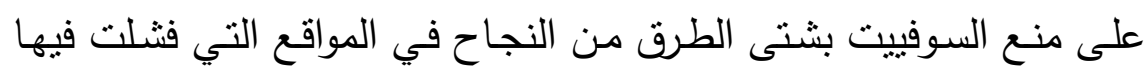

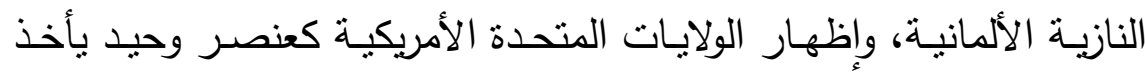

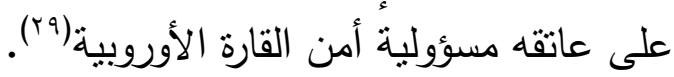

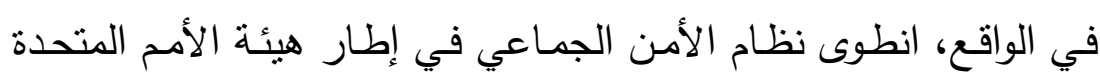

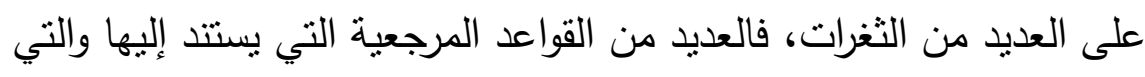

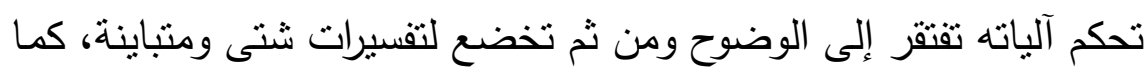

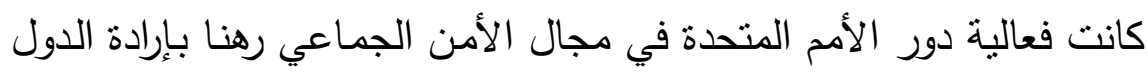
الأعضاء الدائمين في مجلس الأمن الدولي.

\section{الواقع الأمَني الأورويي بعد الحرب الباردة}

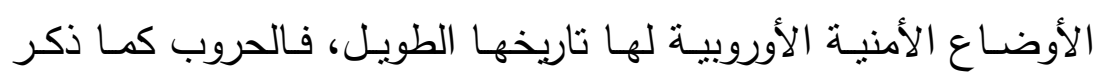

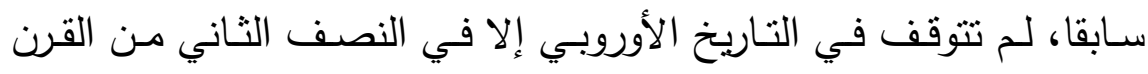

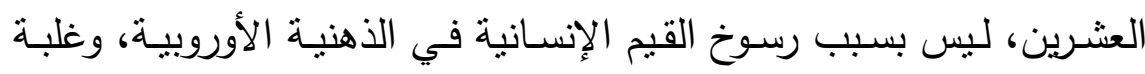

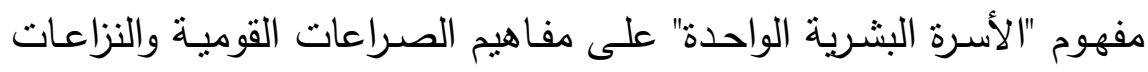

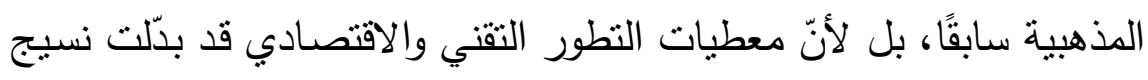

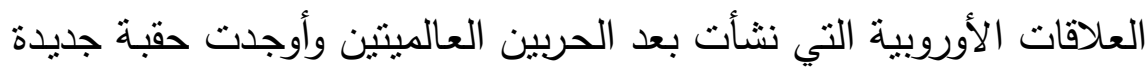

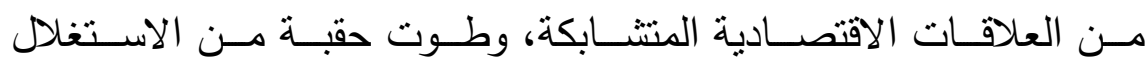




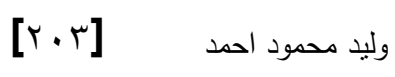
تطورات الأمن الأوروبي

الاستعماري، فأتسـت تبعـا لذلك آفاق التجارة الدوليـة وأمكن معها تعبئة

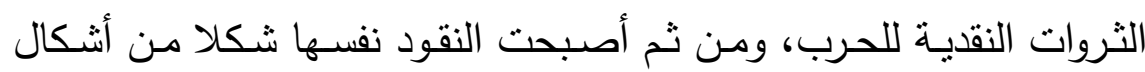
القوة.(r.).

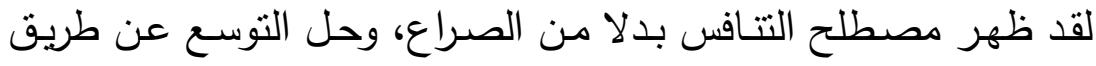

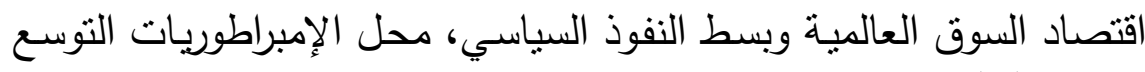

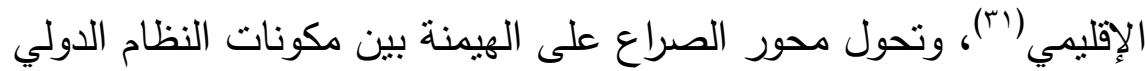

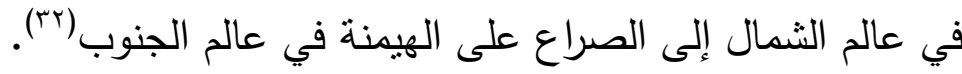

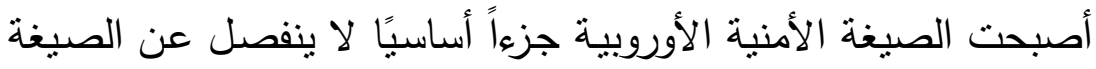

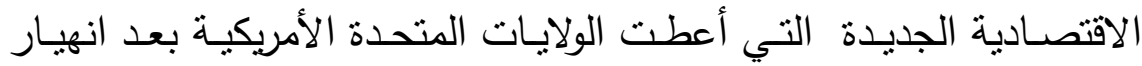

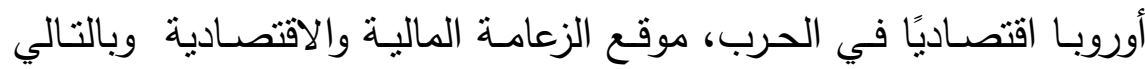

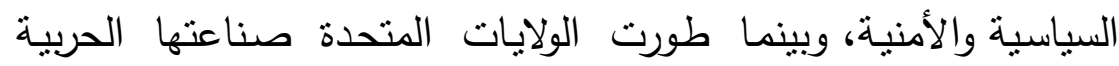

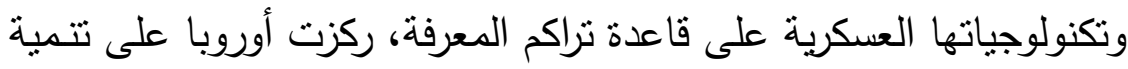

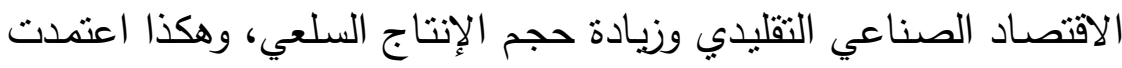

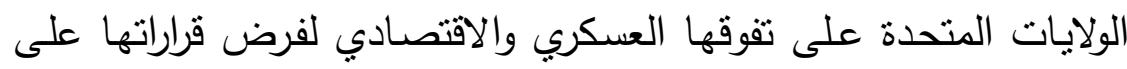

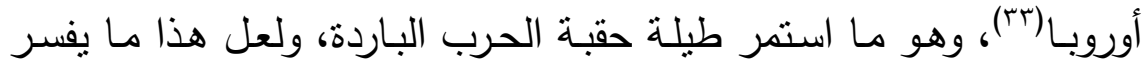

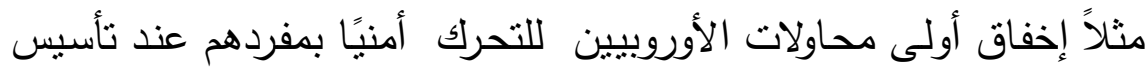

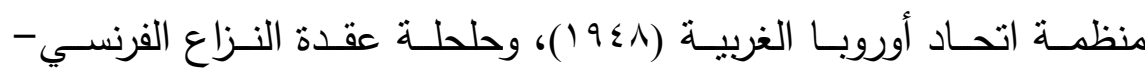

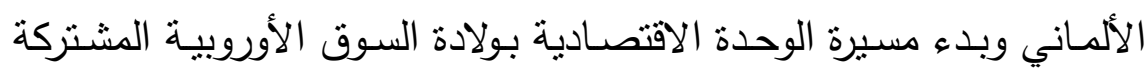

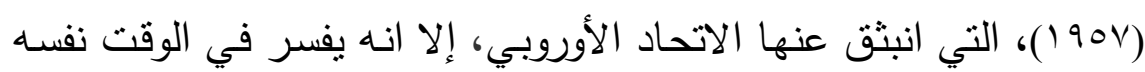

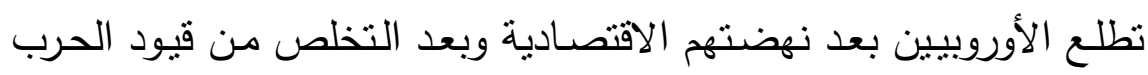

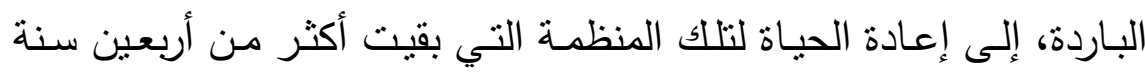

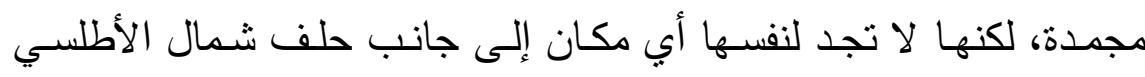

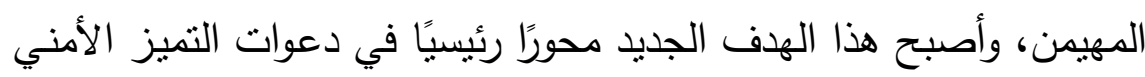

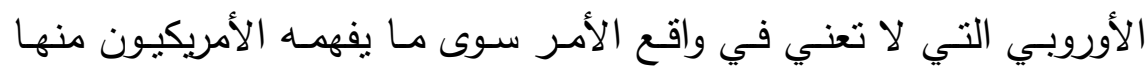
تماماً، وهو الاستقلال بالقرار الأمني العسكري أوروبيًا بعيداً عن الزعامـة لأنس 


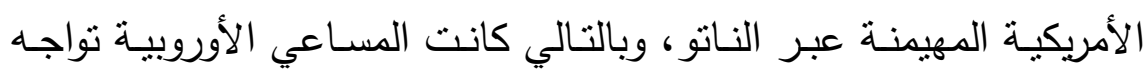

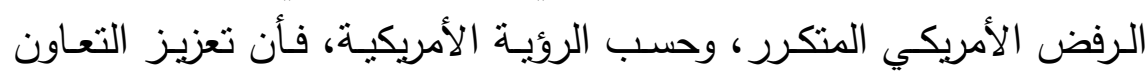

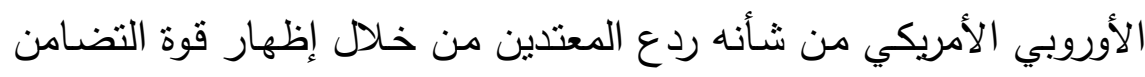

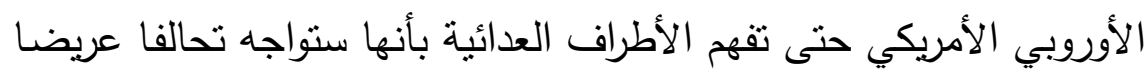

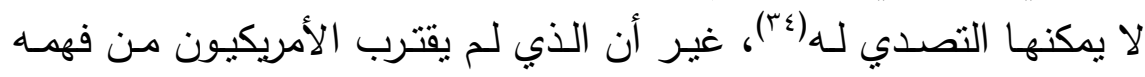

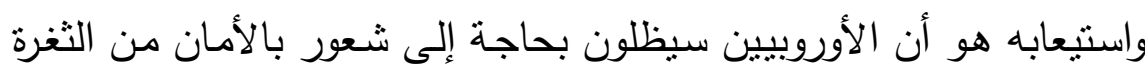

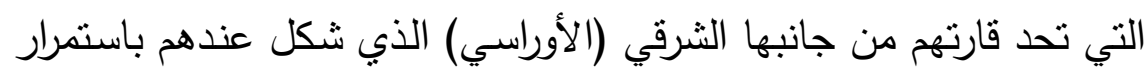

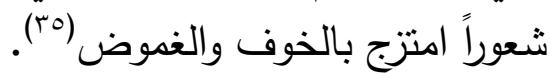
بالمقابل لم يكن لدى الأوروبيين تصور كاف الثبن عن المتغيرات التي حصلت

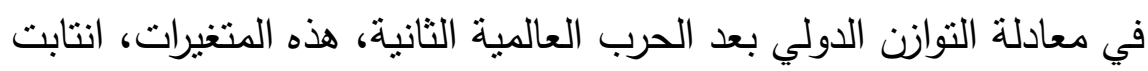

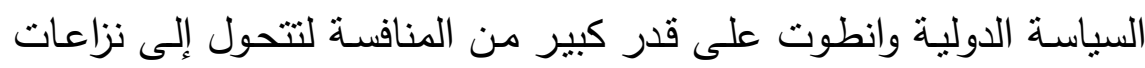

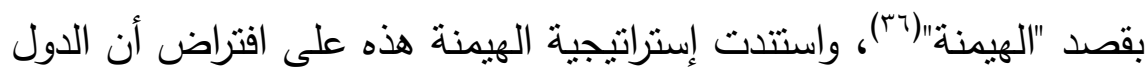

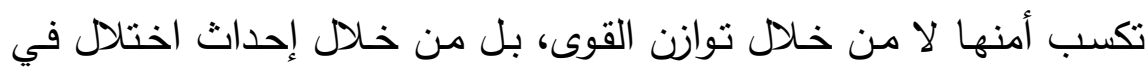

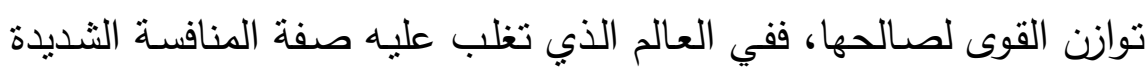

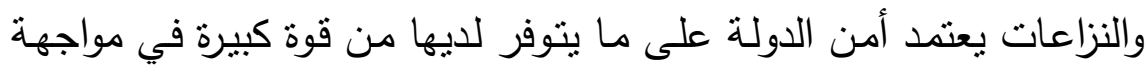

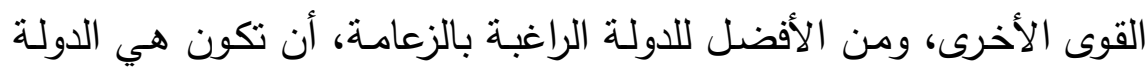

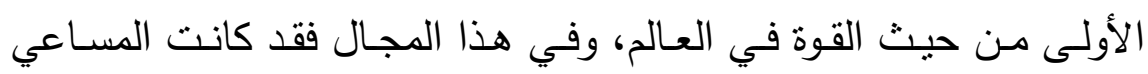

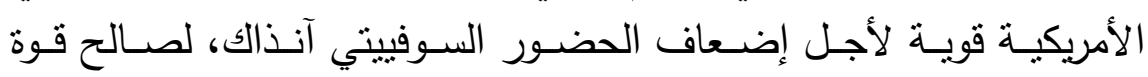

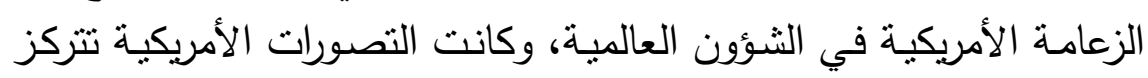

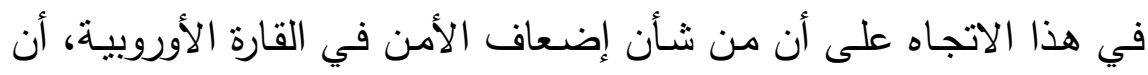

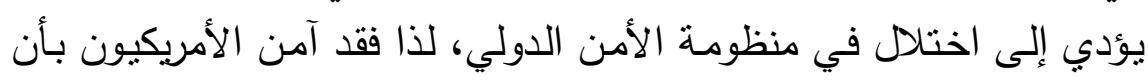

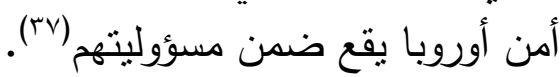

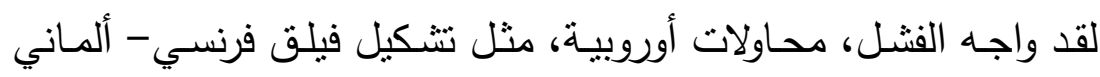

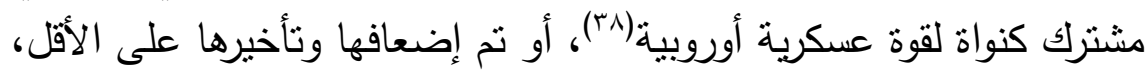

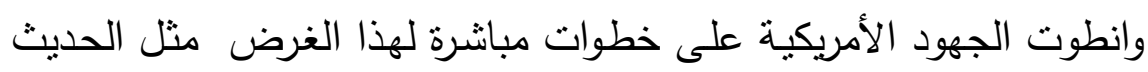




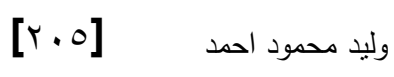

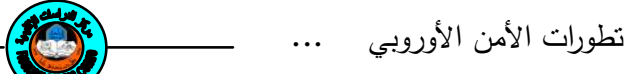

عن خطر (نكسـة محتملـة لروسيا) تعود بها إلى عصدر الهيمنـة وحكم

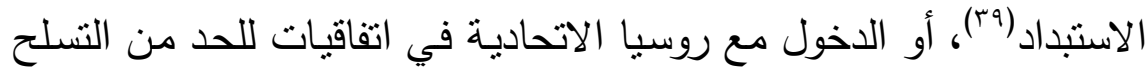

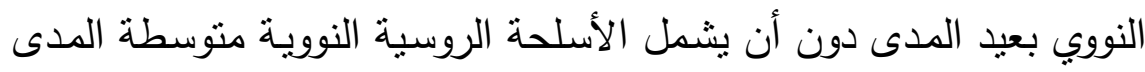

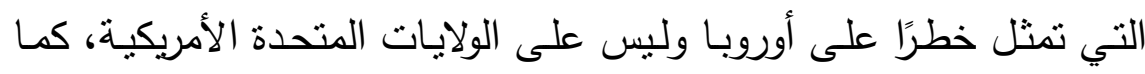

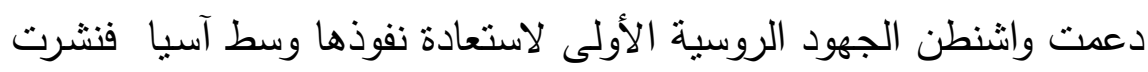

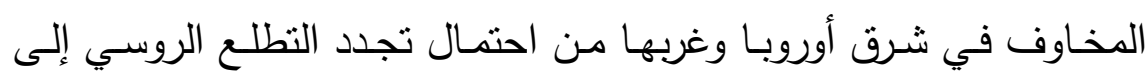

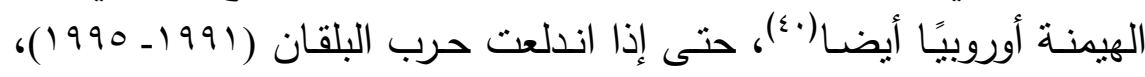

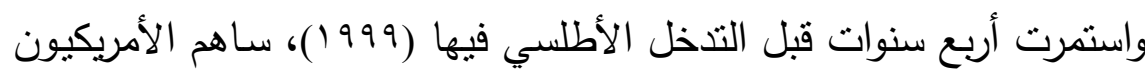

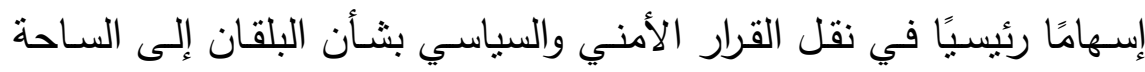

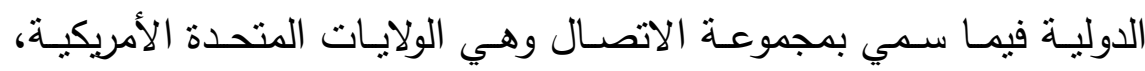

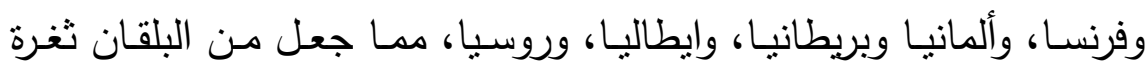

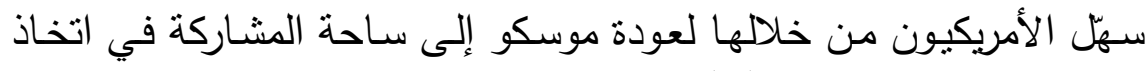

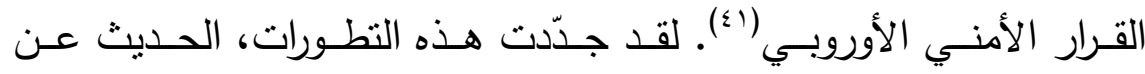

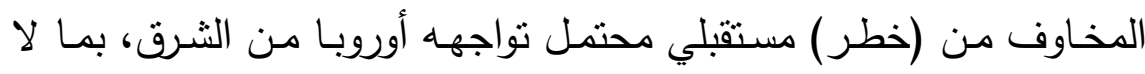

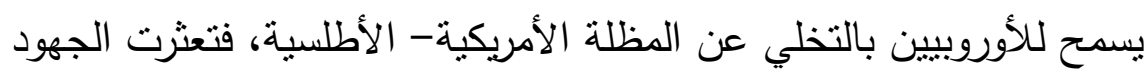

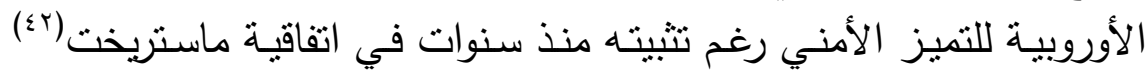

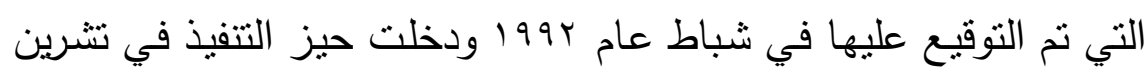
الثاني عام بو 199، وأنشئت السياسة الأمنية والخارجية المشتركة للاتحاد.

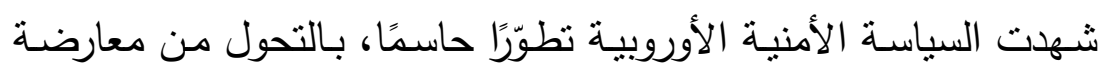

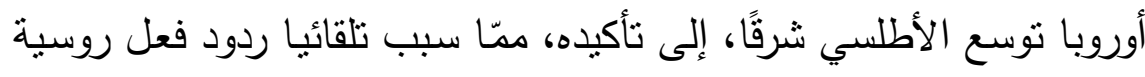

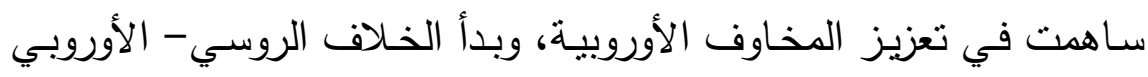

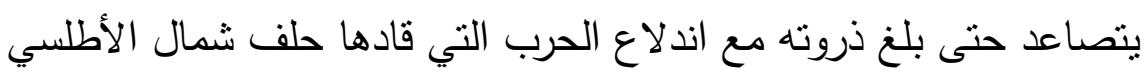

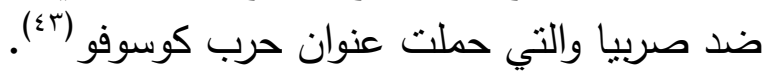


على ضوء ما سبق يمكن تحديد عناصر الصيغة الأمنية الأوروبية الراهنة

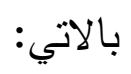

ا ــ مـا تزال أوروبا مرتبطة بسياستها الأمنية وتنلحها ارتباطًا وثثيًا بحف شمال الأطلسي.

r- لا يتوقع أن تسفر جهود التميز الأمني الأوروبي عن النجاح باتخاذ الأنياذ

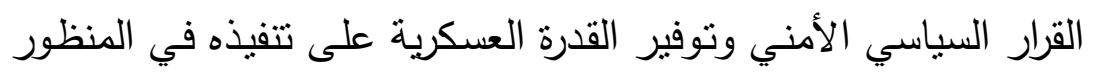

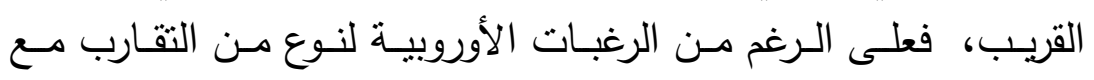

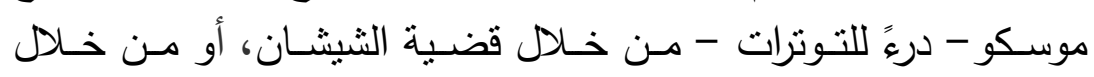

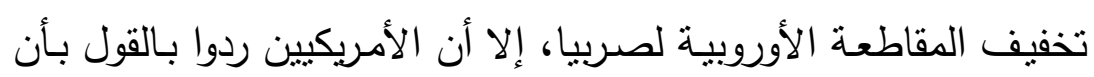

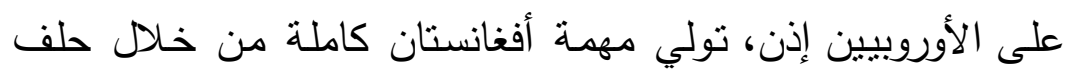
الأطلسي (؛ §).

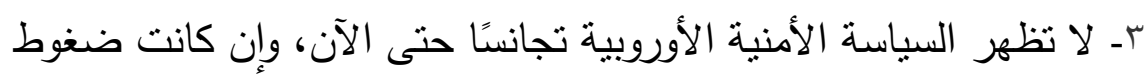

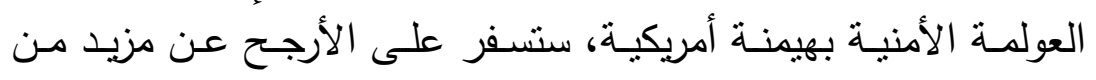

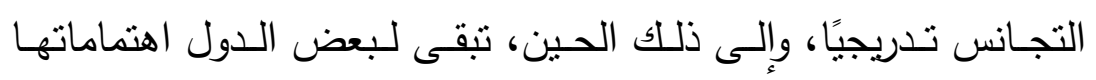

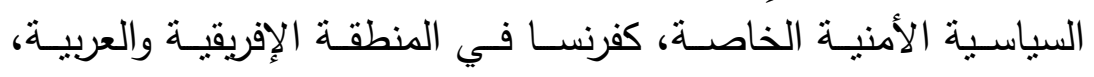

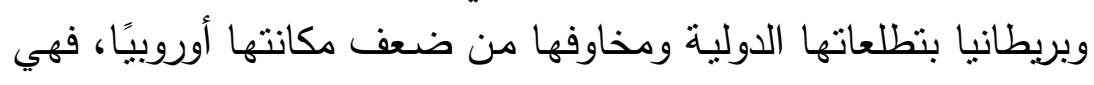

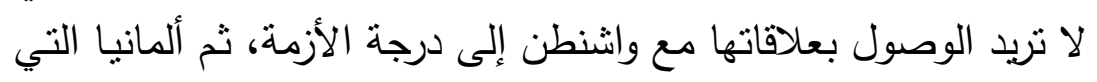

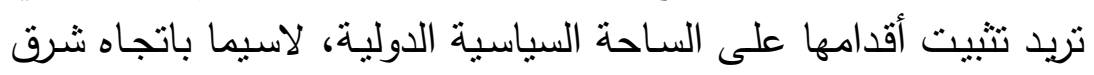

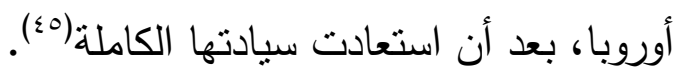

\section{مستقبل الأمن في أورويا حسب التصورات الأوروبية}

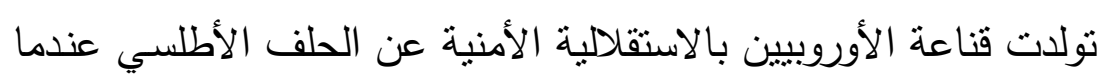

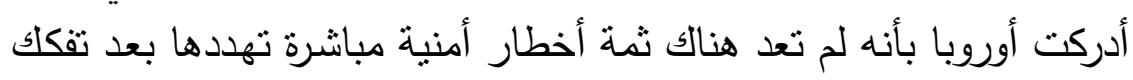

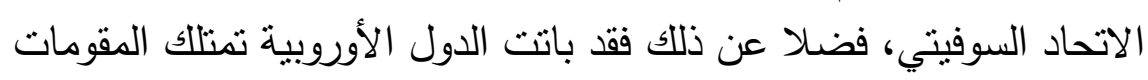
العسكرية والأمنية التي تسمح لها بالدفاع عن نفسها ضد أية تهديدات الأن أنسات أمنية 


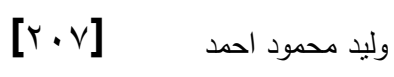
تطورات الأمن الأوروبي

خارجية، وأن تحتوي أيضًا أية تهديدات أمنية من داخل المنطقة، وأصبحت

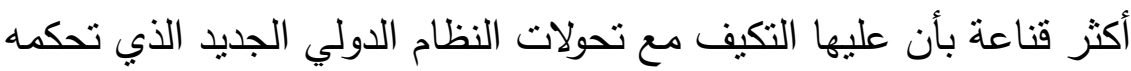

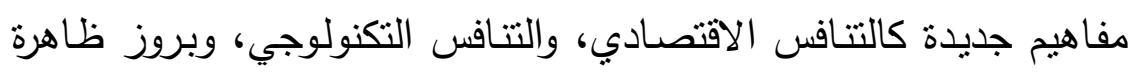

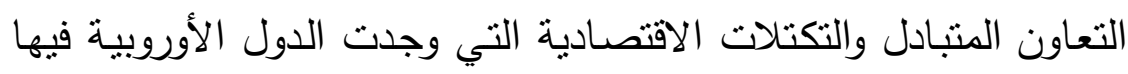

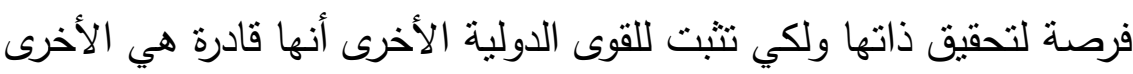

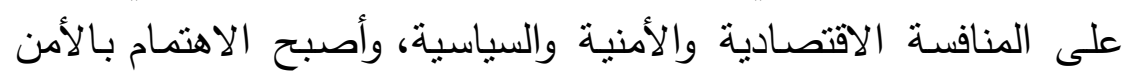

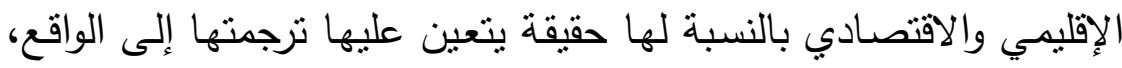

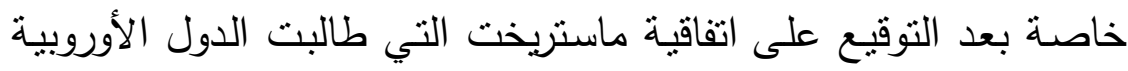

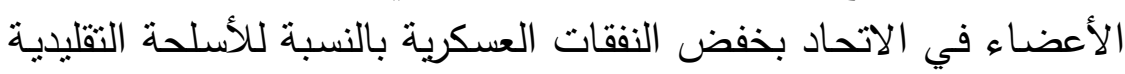

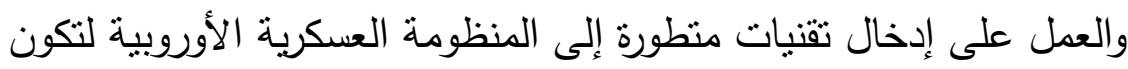

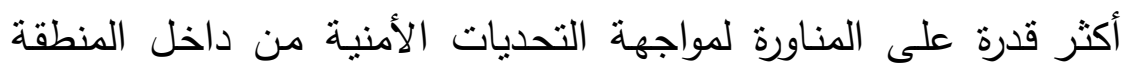

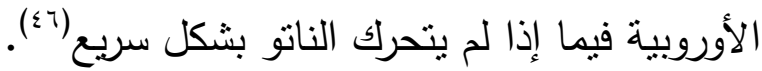

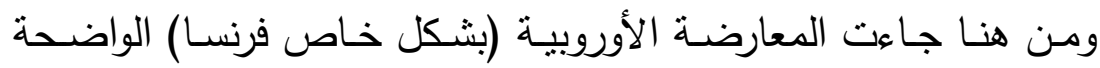

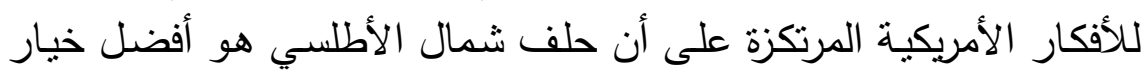

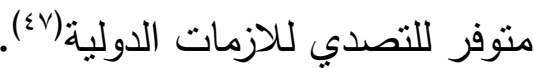

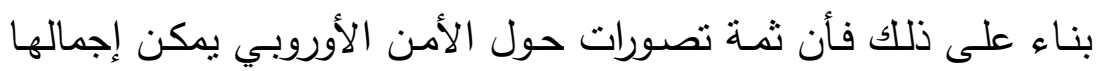
بالرؤى الآتية: الروئية البريطانية التي تؤكد على فكرة أوروبا ذات الاتمتداد الاقتصادي

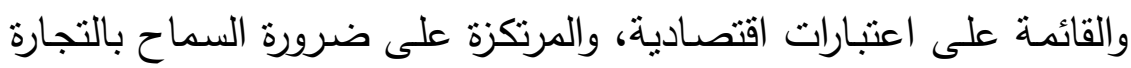

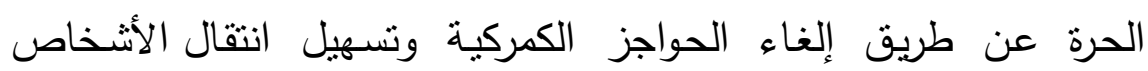

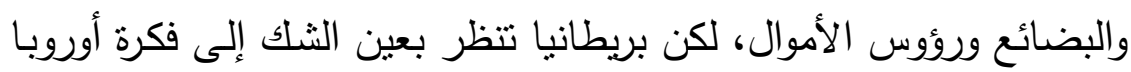

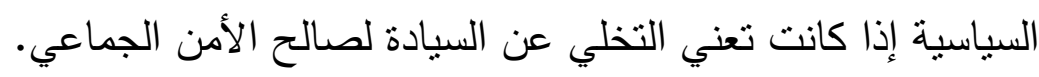

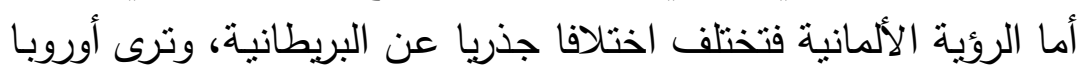

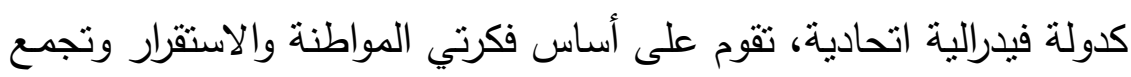


بين مجتمعات متضامنة ونموذجية توحد مصيرها من أجل تأمين الاستقرار الأمني. بدورها ترى فرنسا وإلى حد ما أسبانيا، أن أوروبا هي القوة المدعوة لأن

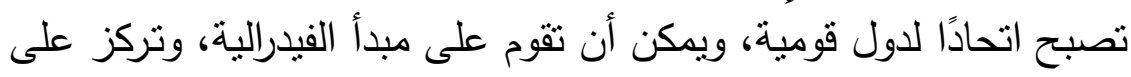

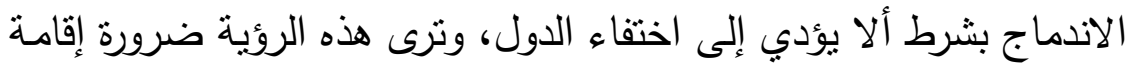

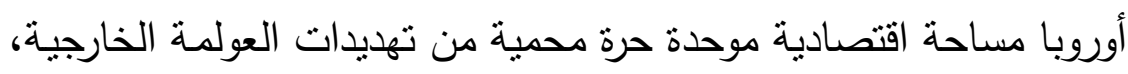

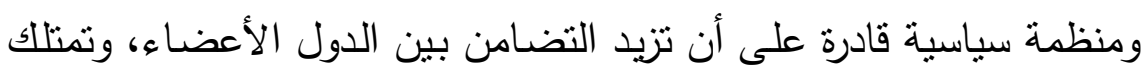

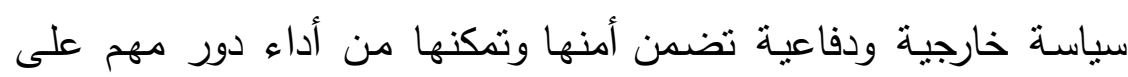
الساحة الدولية(£).

على الرغم من وجود مؤسسة عسكرية تابعة للاتحاد" اتحاد أوروبا الغربية

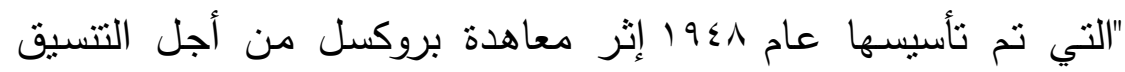

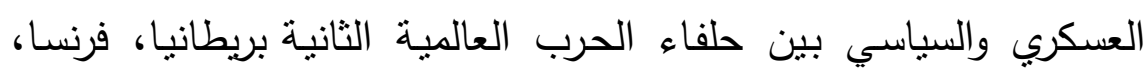

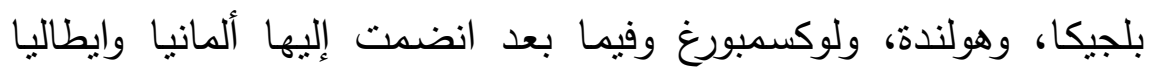

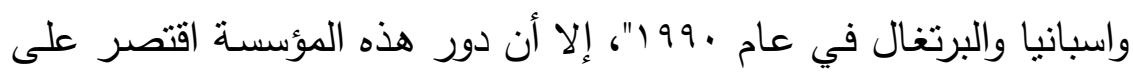

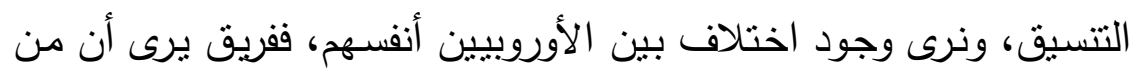

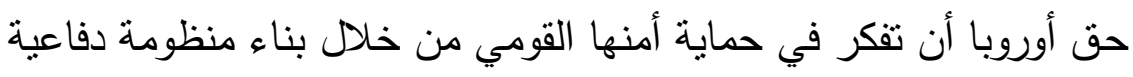

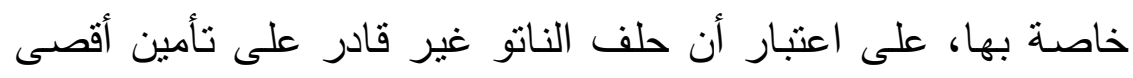

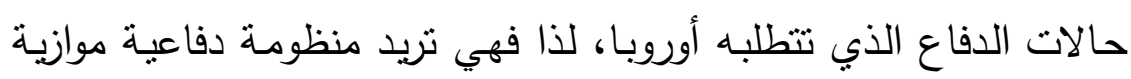

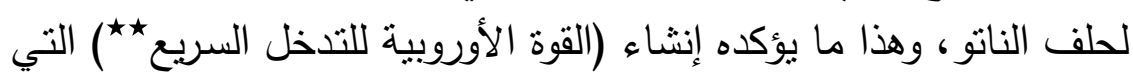

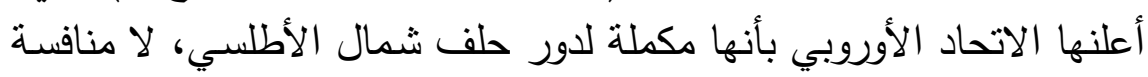
(ะ9) ل्य

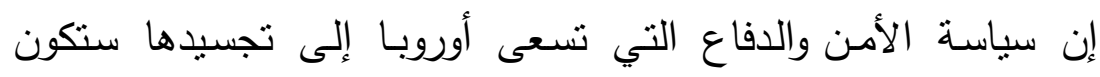

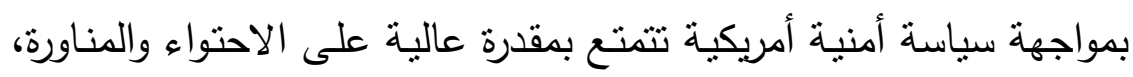

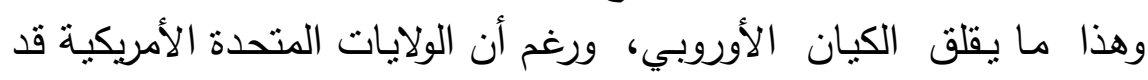

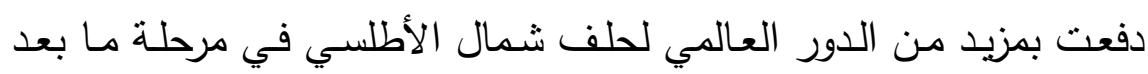


الحرب الباردة، إلا أن الأوروبيين وخصوصا الفرنسيين حاولوا الحد من هذا

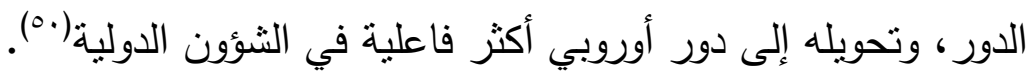

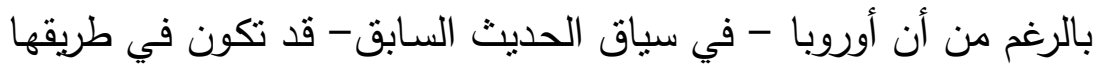

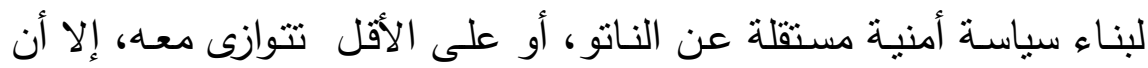

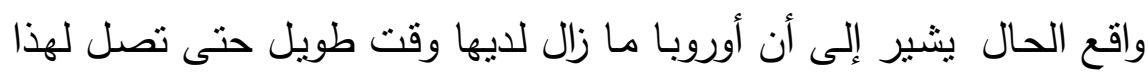

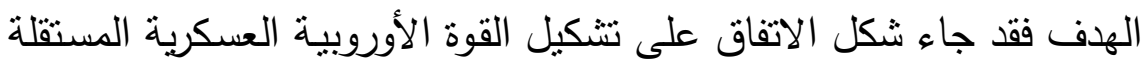

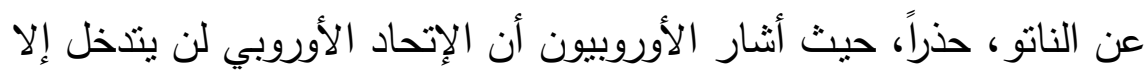

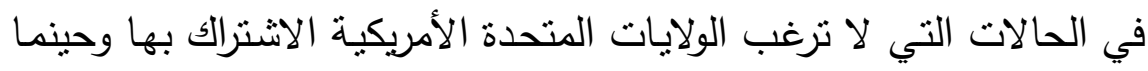

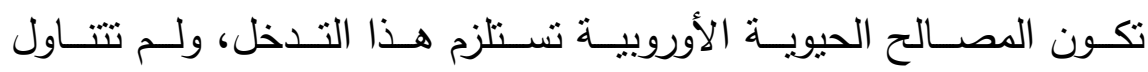

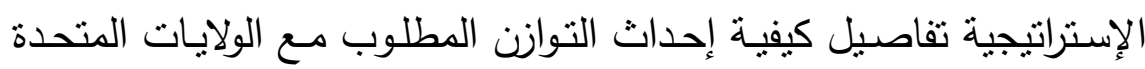

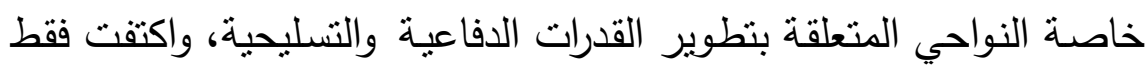

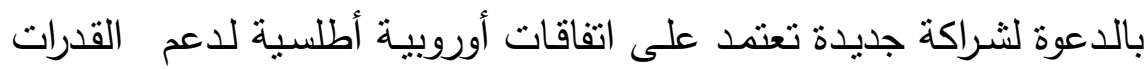

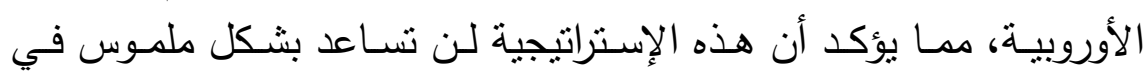

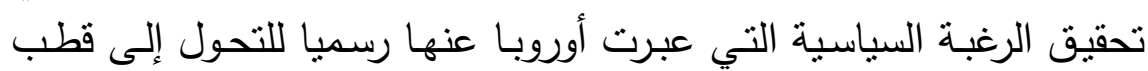
عالمي يدعو للتعددية الفاعلة (1).

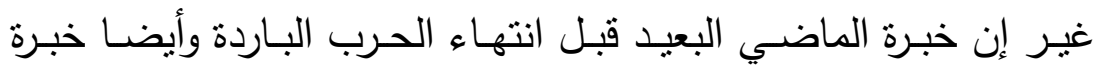

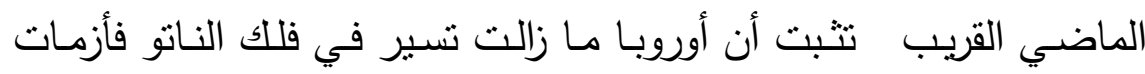

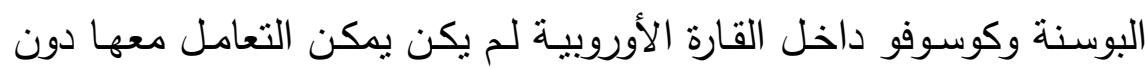

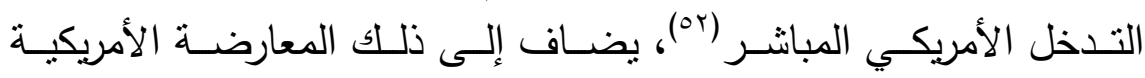

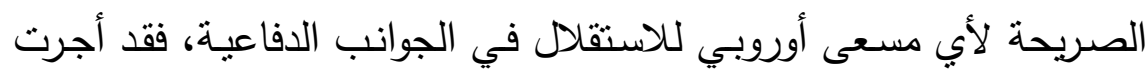

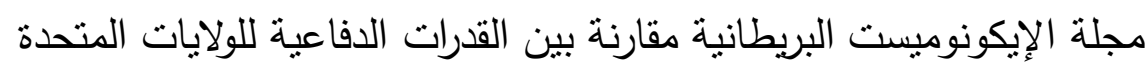

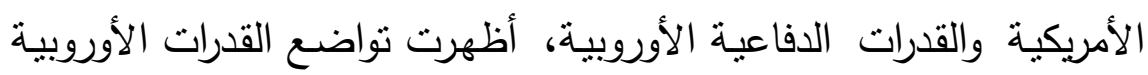

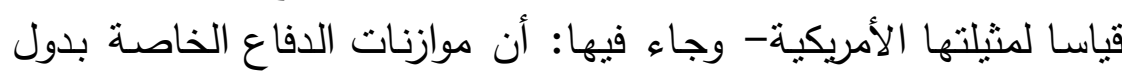

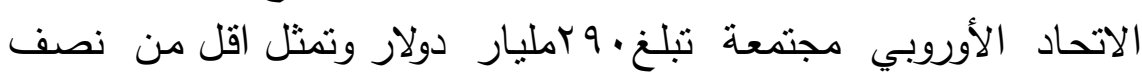

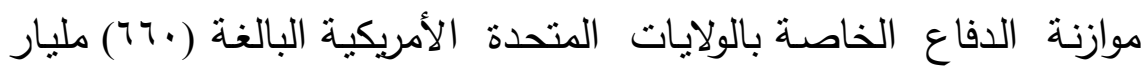




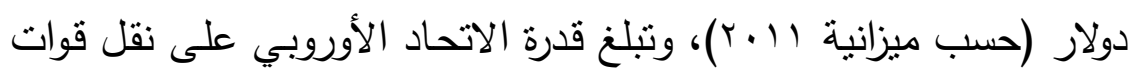

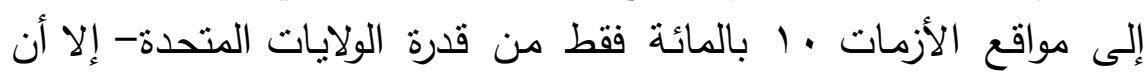

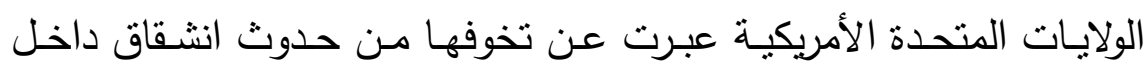

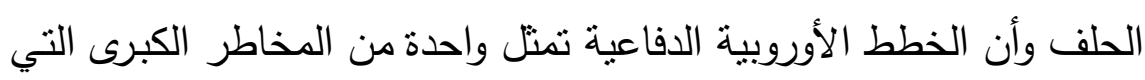

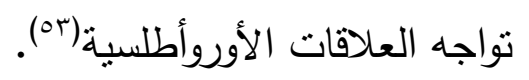

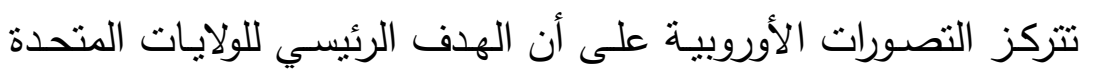

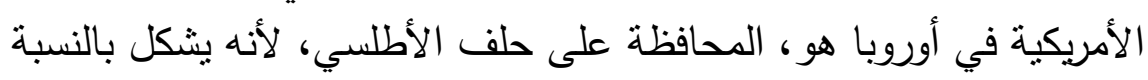

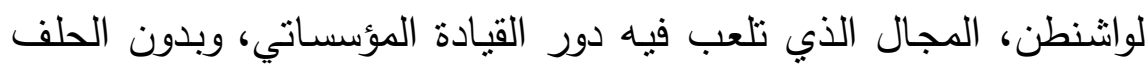

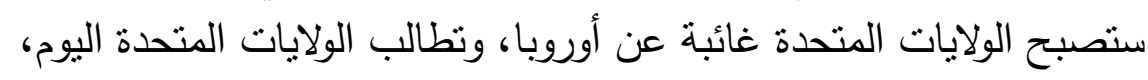

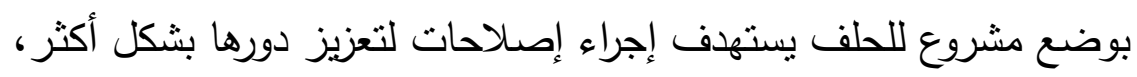

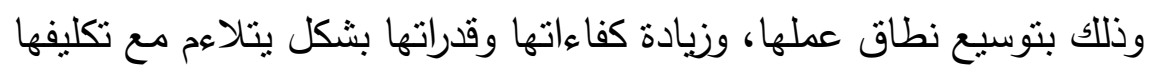

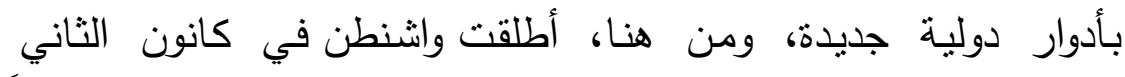

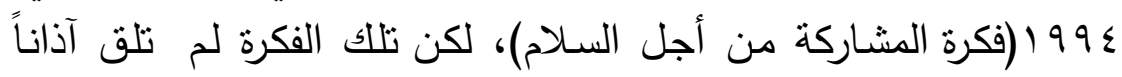

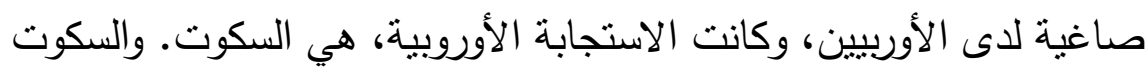

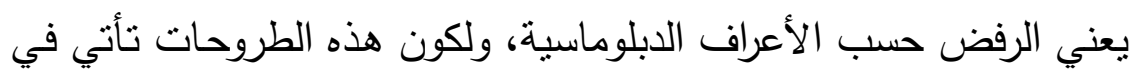

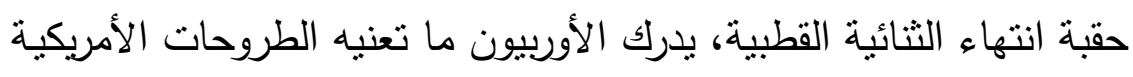

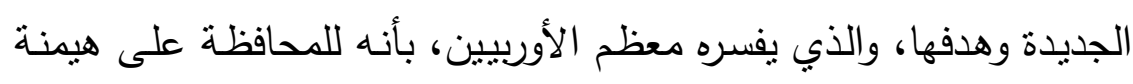

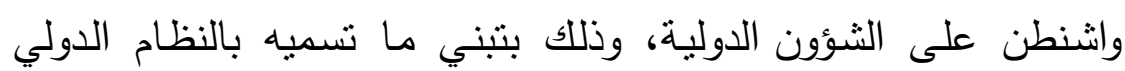

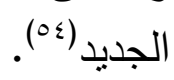

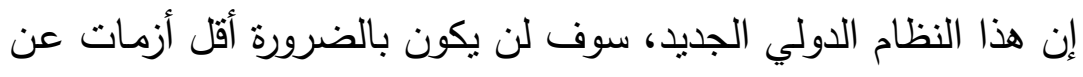

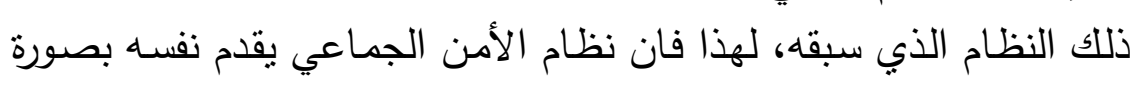

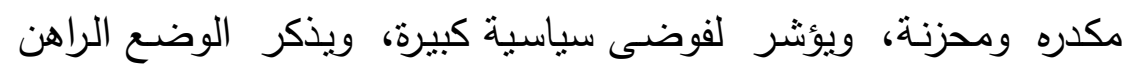

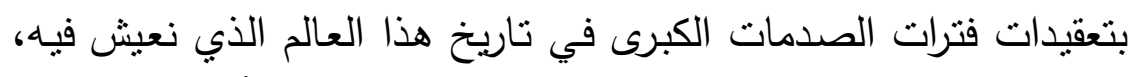

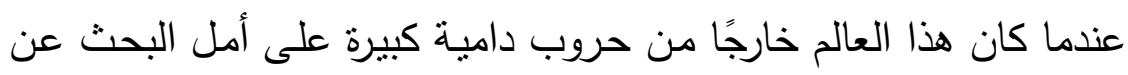
الاستقرار ، وعن توازن للقوى العالمية (00). 
بينمـا كانت قضية الأمسن في أوروبـا منذ مؤتتمر ويستفاليا وحتى قيام

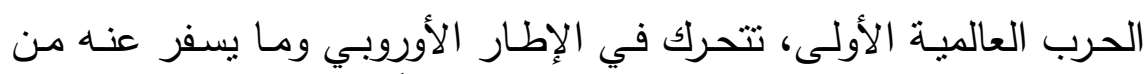

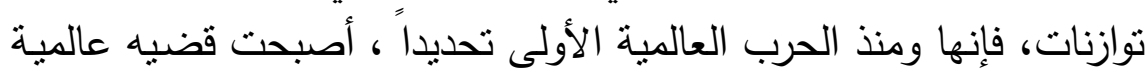
تدخل في إطار منظومة الأمن العالمي.

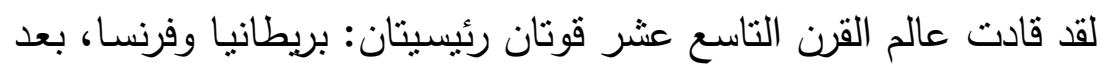

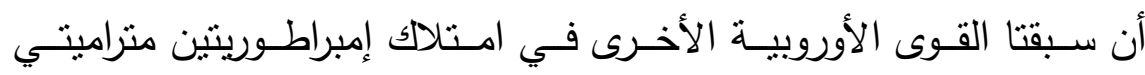

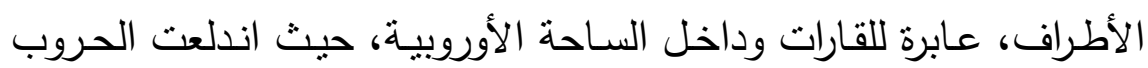
طوال قرون.

كان توازن القوى الذي تأسس بعد الحروب النابليونية مـا زال مستقراً،

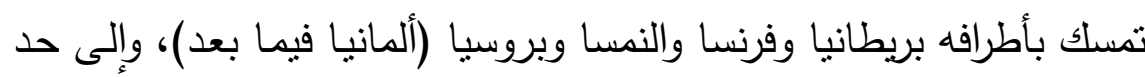

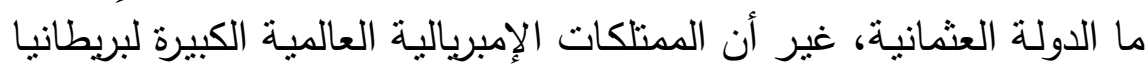

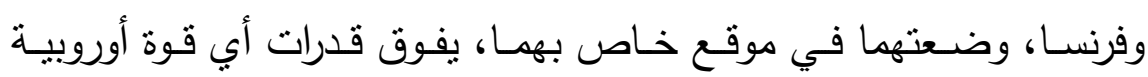

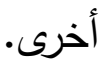

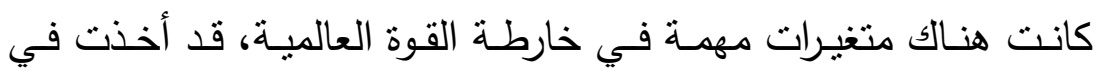

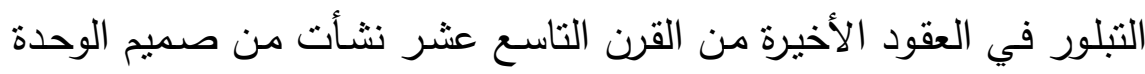

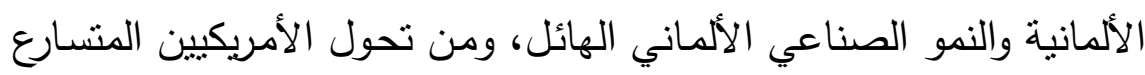

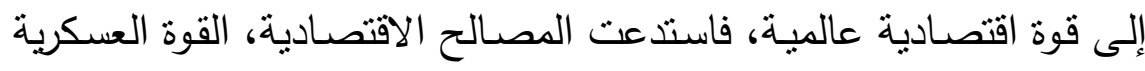


ليس لتوفير الحماية وحسب، بل ولتعظيم الموارد والأسواق كذلك. وهكذا ما

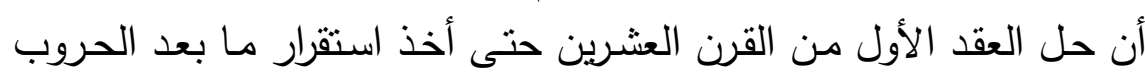

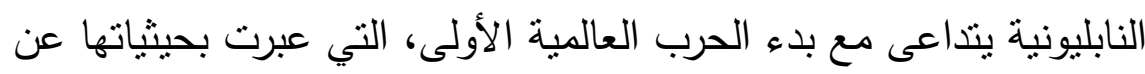

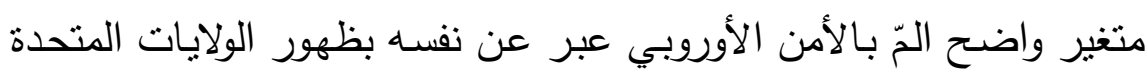

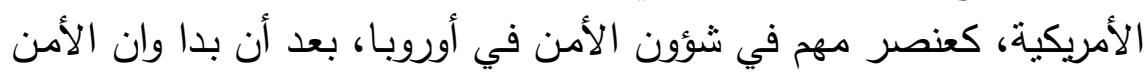

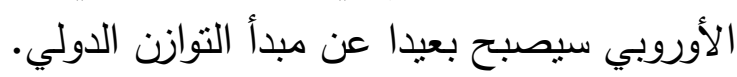
تبعا لذلك ظلت آليات ومؤسسات الأمن الأوروبي قاصدرة عن مجاراة

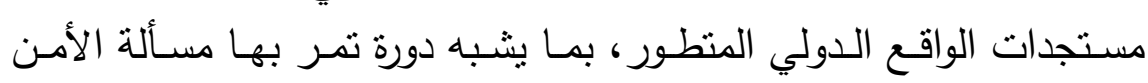

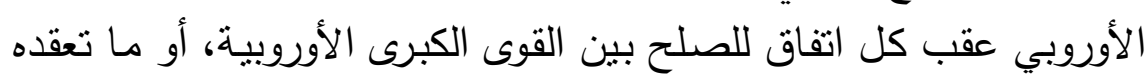

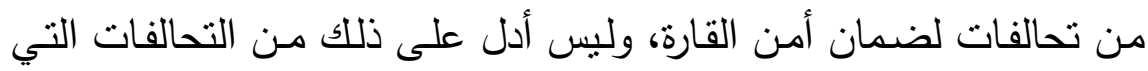

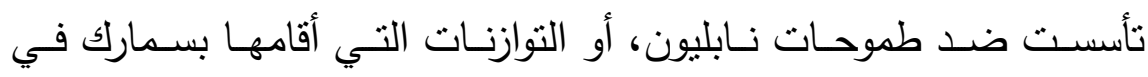
النصف الثاني من القرن التاسـع عشر ، أو الاتفاقيات التي خلفتها معاهدات

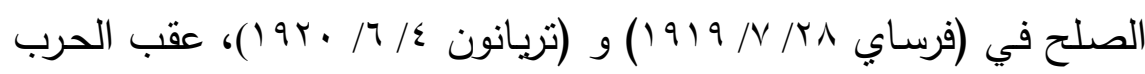

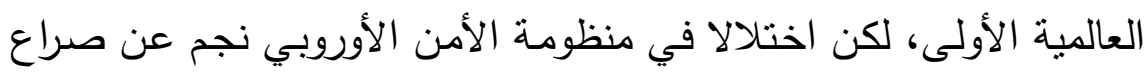

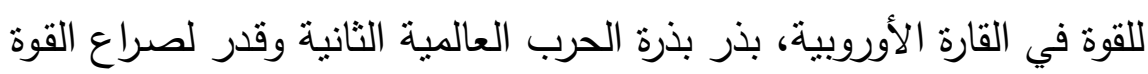

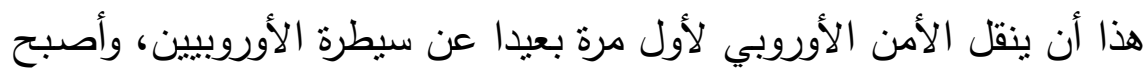

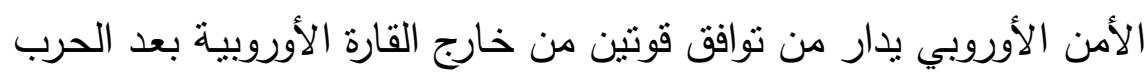
العالمية الثانية.

اللافت هنا، انه ولأول مرة يشهد الأمن الأوروبي هذه الفترة من السكون امتذت منذ انتهاء الحرب العالمية الثانية، وهذا الهدوء يعود في جانب منه الأبه

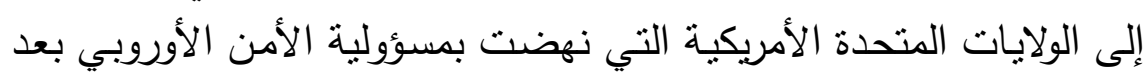

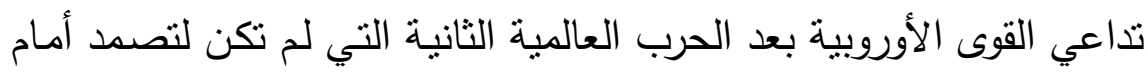
الاندفاع الثيوعي، الأمر الذي اوجد حقبة الحرب الباردة.

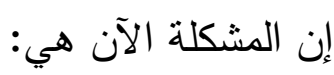


هل مازالت مؤسسات وآليات الأمن الأوروبي، الموروثة عن حقبة الحرب

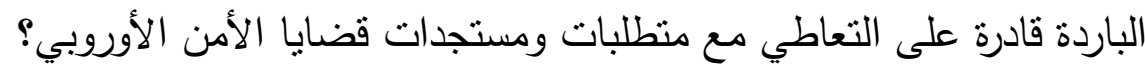

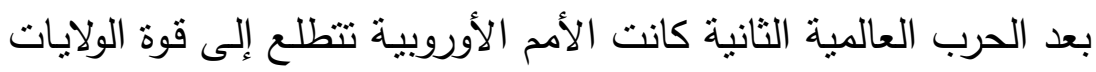

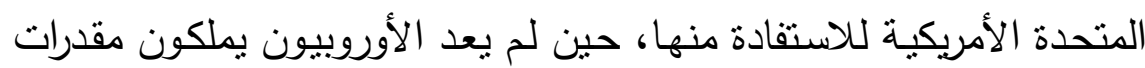

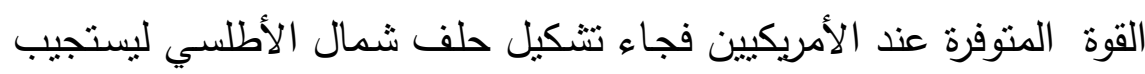

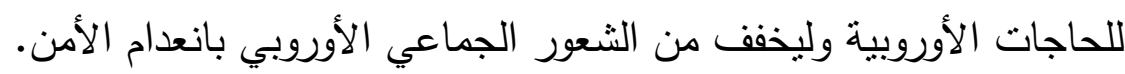

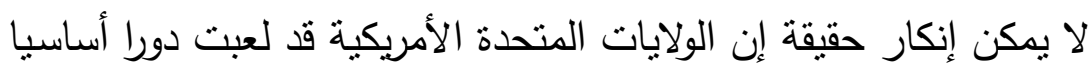

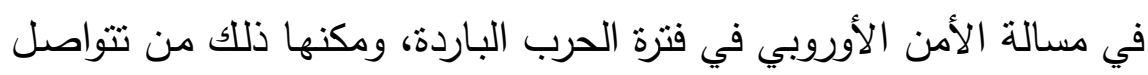

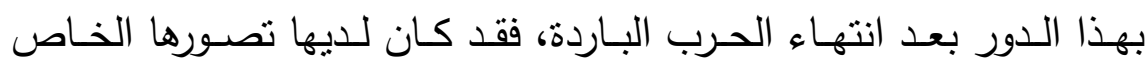
بمسائل الأمن الأوروبي وما يتصل بها منل توسيع حلف شمال التهال الأطلسي. لقد طرحت قضية ضم دول شرق ووسط أوروبا إلى المنظومة الأوروبية،

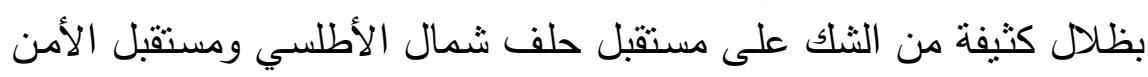
الأوروبي بشكل عام بعد مرحلة الحرب الباردة.

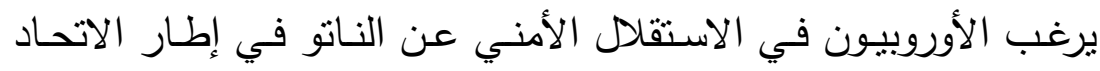

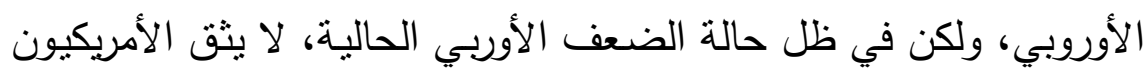

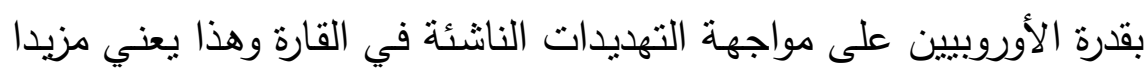

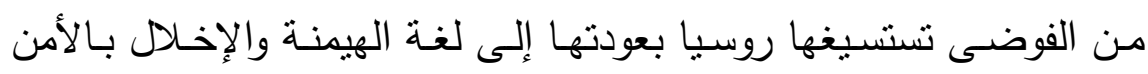

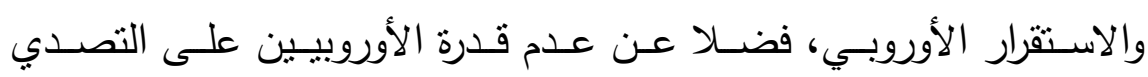

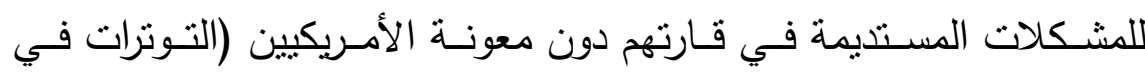
البلقان) وغيرها. لا يخفي الأمريكيين امتعاضهم وخشيتهم من هكذا تطلعات، فهم لاثقون

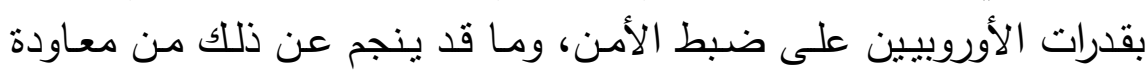
أجواء الحرب الباردة للظهور مرة ثانية. 


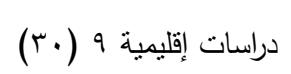

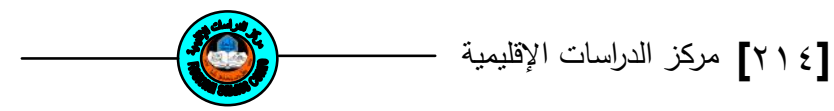

\title{
European Security Developments
}

\author{
Waleed Mahmood Almed \\ Department of Political and Strategic Studies \\ Regional Studies Center \University of Mosul
}

\begin{abstract}
The concept of European security witnessed variables mission that began since the Westphalia, which established a new concept in international relations was based on the sovereignty of States, and founded the balance of power, and played the European countries a key role in international security, when Europe was controlled by the balance of world powers until the outbreak of World War II, but global balance of power after the war moved from the European continent to the outside, and even became a European security, however, the two Soviet and American cold War period, and then took another twist on the European Security after the Cold War, representing the transition from the world when he was European security means security of international to the continental European security is no longer refers to international security, the concept of the sovereignty of States, founded by the Conference of Westphalia "thing" of the past.

There is a paradox in European thought on this issue, after the First World War began to Europe is looking to get rid of its recent past based on the glorification of force and arms, but after the American hegemony, seems more nostalgic to look for defensive capabilities confirming their presence in the vision of twenty-first century.
\end{abstract}


[ $r, 0]$

$$
\text { نطورات الأمن الأوروبي ... }
$$

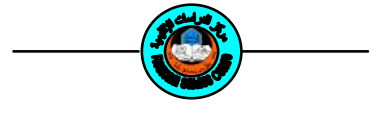

(1) Barry Buzan: People, States and Fear: An Agenda for International Security Studies in The Post-cold War Era. (London: 1991), p.190

$$
\text { (*) ويستفاليا، هي مقاطعة في شمال ألمانيا . }
$$

(2) Andreas Osiander: Sovereignty," International Relations, and the Westphalian Myth ", International Organization review, vol, 55, no, 2, Spring 2001, ( Massachusetts: 2001), p.251

(3) William Doyle: the oxford history of the French revolution, (London: 1989), pp.132-158

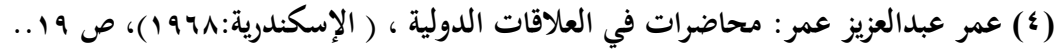

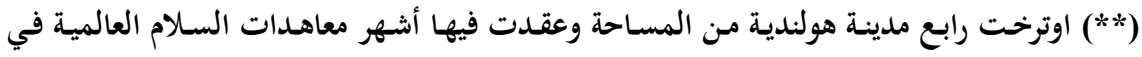

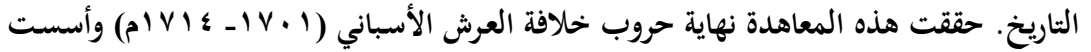

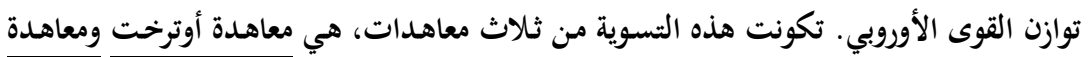

$$
\text { راستات ومعاهدة بادن }
$$

(5) Inken Schmidt: "The Reverberations of Peace" The Utrecht egotiations and the Holy Roman Empire in Rethinking the Peace of Utrecht 1713, (Osnabrück: 2011), p.12

$$
\begin{aligned}
& \text { ( ) }
\end{aligned}
$$

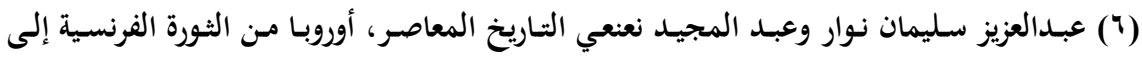

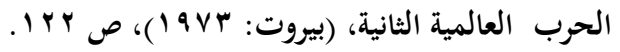

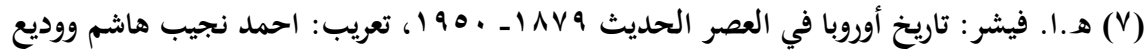

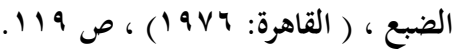

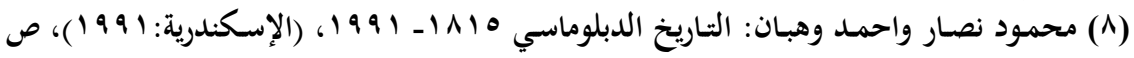

$$
\begin{aligned}
& \text {. }\{9
\end{aligned}
$$

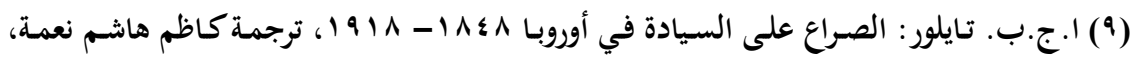

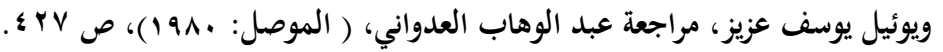

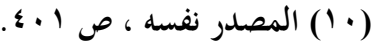

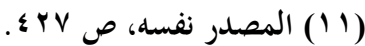

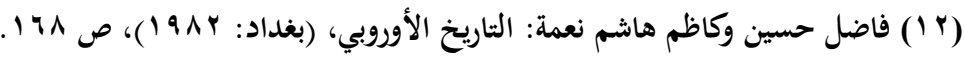

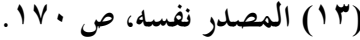

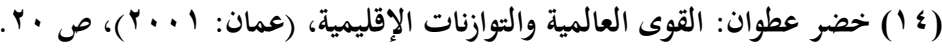

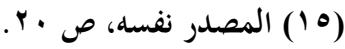




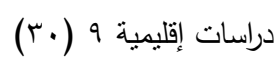

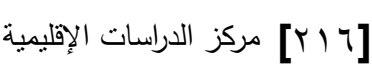

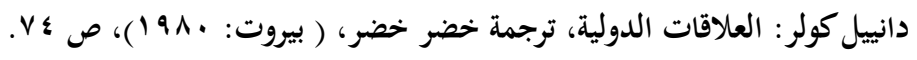

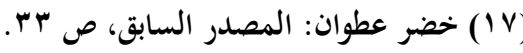

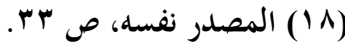

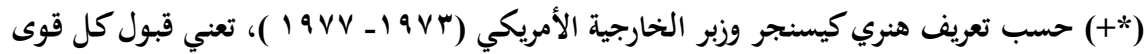

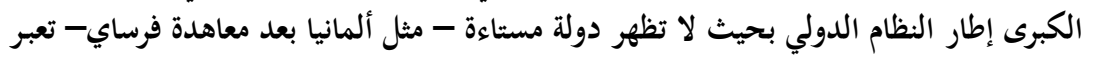

عن استيائها بانتهاج سياسة خارجية متطرفة.

(9 (1) روبرت غلين: الحرب والتغيير في السياسة العالميسة، ترجمة عمر سعيد الأيوبي، (بيروت:

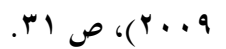

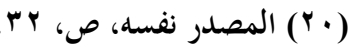

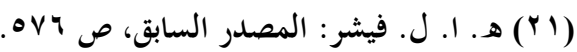

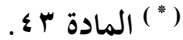

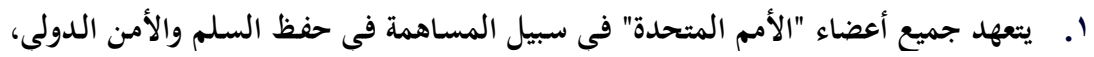

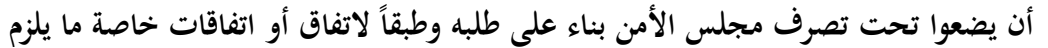

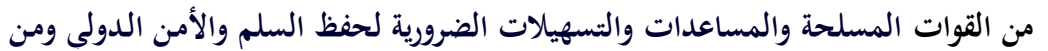

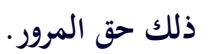

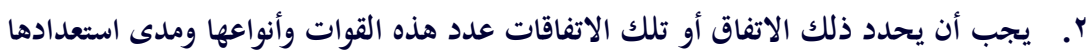

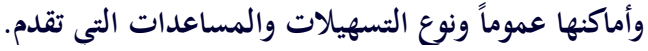

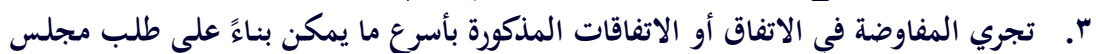

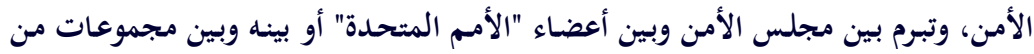

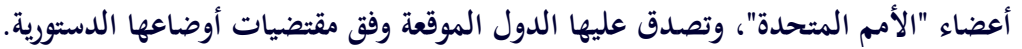

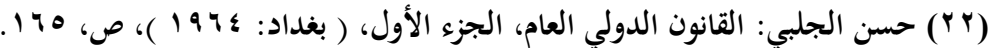

(23) Edward Hallett Carr: the twenty years crises 1919-1939, an introduction to the study of international relations, (London:1951), p.132

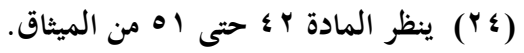

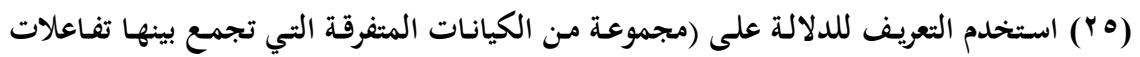

$$
\text { منتظمة نتيجة وجود شكل من أشكال السيطرة)، ينظر : }
$$

Robert Mundell \& Alexander Swoboda:monetary problems of international Economy ,(Chicago university:1969), p.343

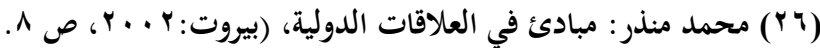

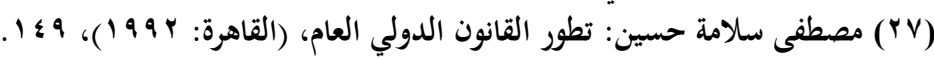

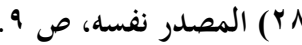

(29) Ricardo Alcfaro \& Erik Jones: European security, (Roma: 2011), P.15

(30) Ralph Hawtery: economic aspects of sovereignty, (London: 1952 ), p.60 
(31) William McNeil: past \& future, (Chicago university: 1954), p.74

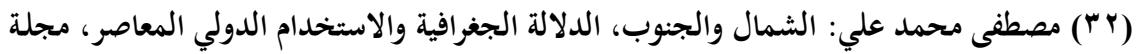

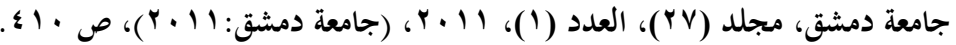

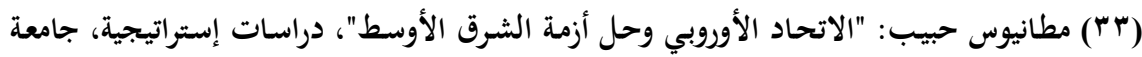

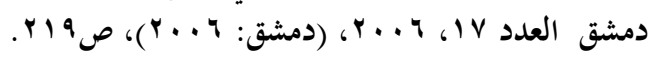

(34) European security: us. and European Contributions to Foster and

Security in Europe, Report to the Congressional Committees,

(Washington: 2001), p. 45.

(35) Ricardo Alcfaro:Op.Cit, p. 45.

(آץ) الهيمنة- أو الزعامة- هي إستراتيجية واقعية تسعى إلى إدامة السيطرة الجيوسياسية ما بعد

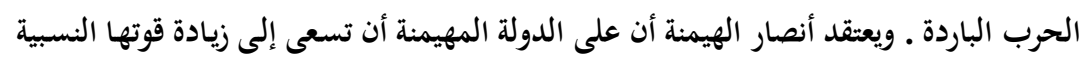

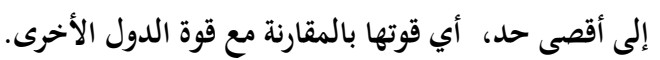

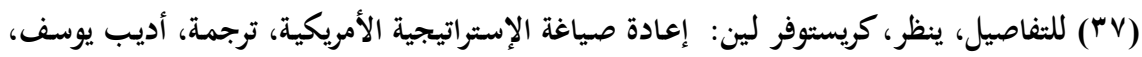

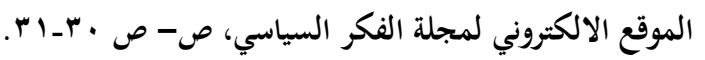

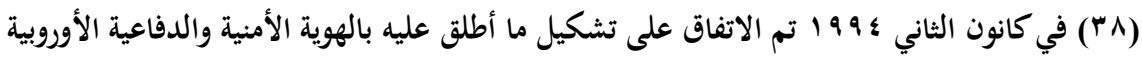

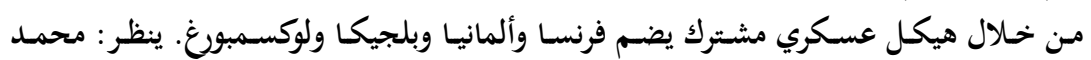

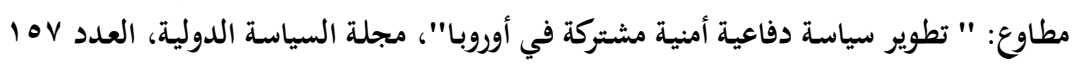

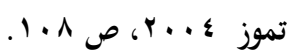

(جq) إن التوصيف الأمريكي للنكسة الروسية المحتملة ينطوي على محاولات الأمريكيين لإظهار

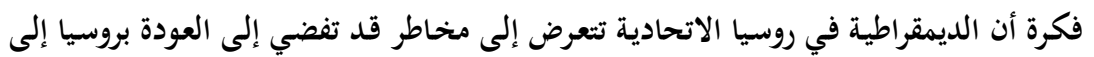

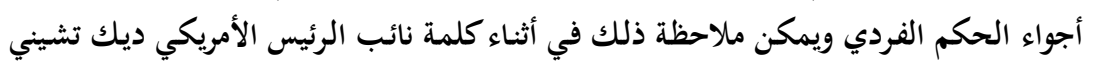

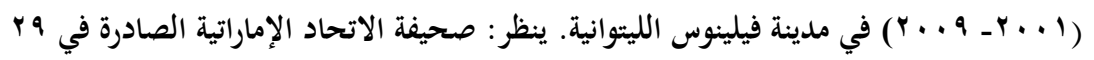

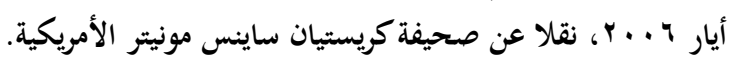

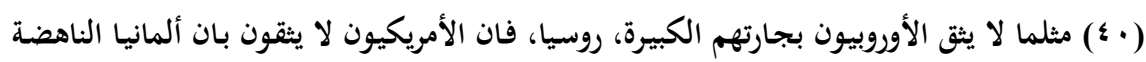

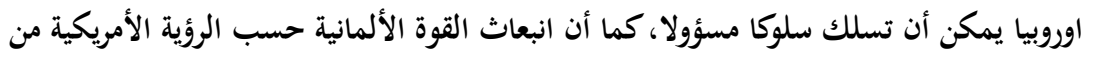

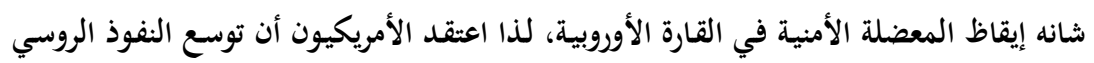

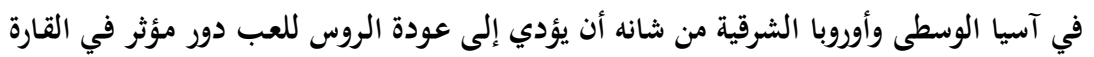

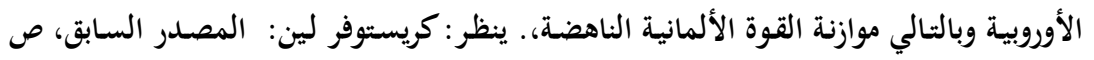




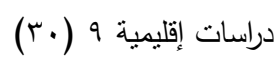
[ركز الدراسات الإقليمية

( ا \&) للتفاصيل عن هذه الأحداث ينظر: إيريك لوران: حرب كوسوفو، الملف السري، (بيروت:

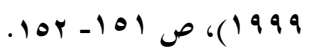

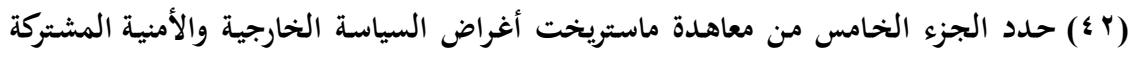

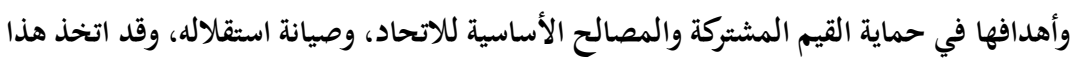

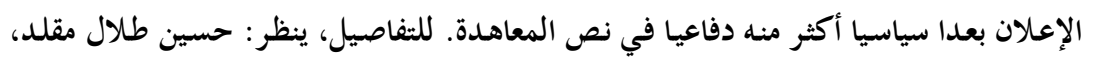

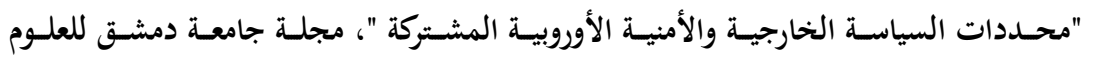

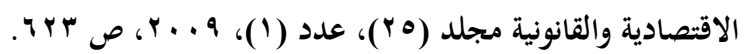

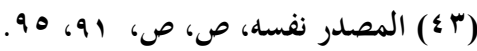

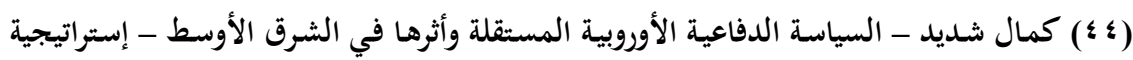

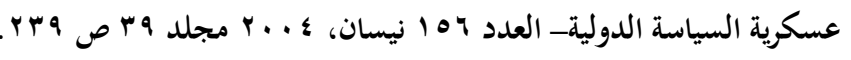

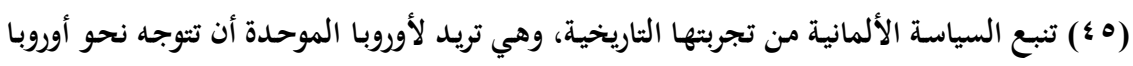

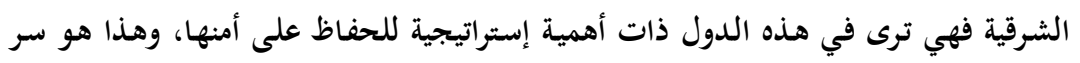

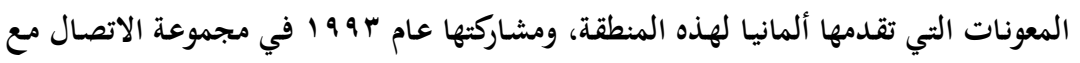

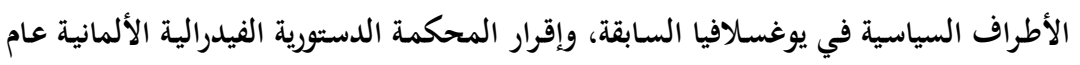

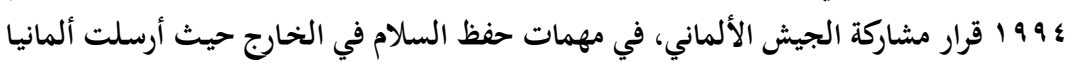

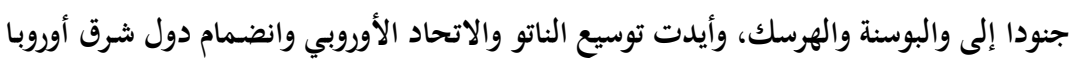

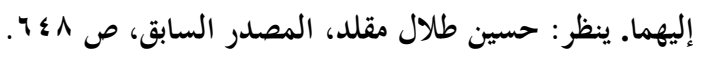

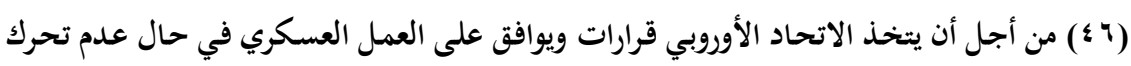

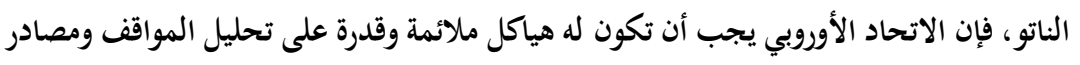

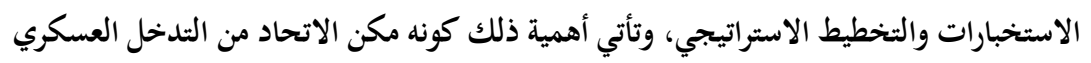

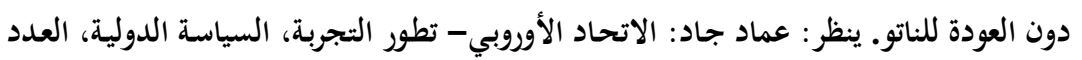

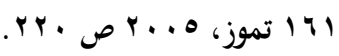

(47) F. Stephen larrabee:"the united states and the European security and defense policy",Rand corporation, year book 2006, (SantaMonica:2006), p.174.

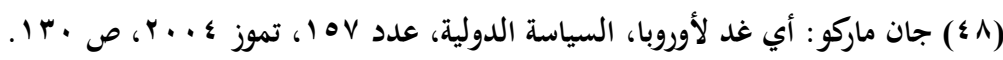

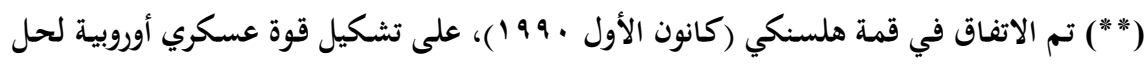

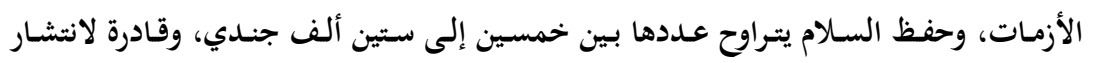




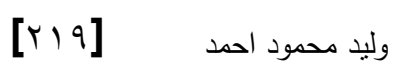
تطورات الأمن الأوروبي خلال ستين يوما ويمكن أن ترابط لمدة تصل إلى عام. ينظر : حسين طلال مقلد، المصدر

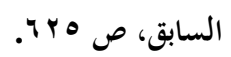

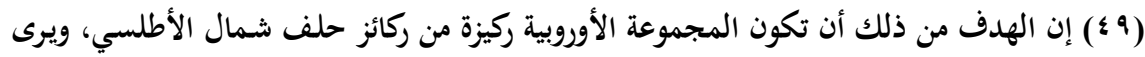

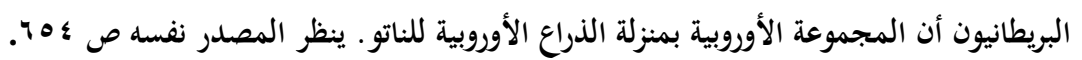
(50) F. Stephen larrabee :Op,Cit,p.175.

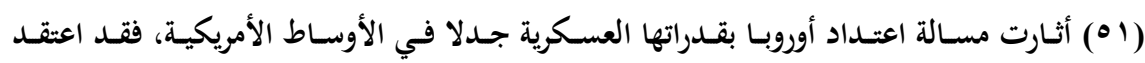

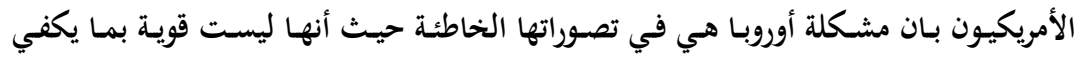

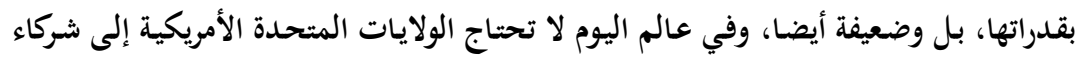

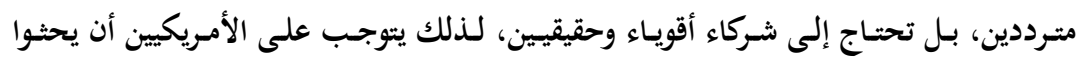

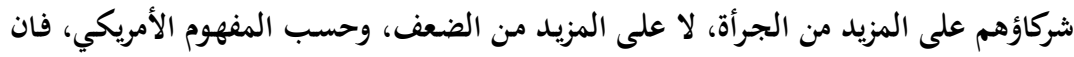

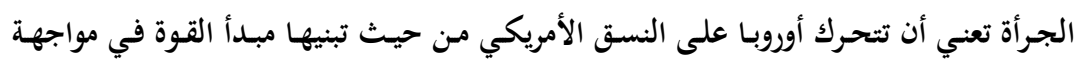

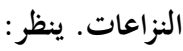

\section{Ibid :p.181}

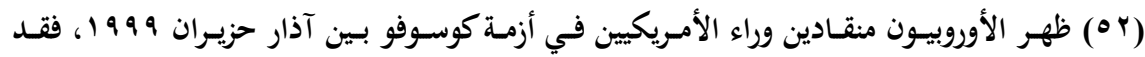

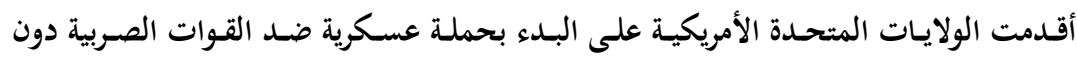

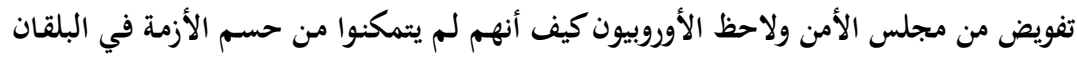

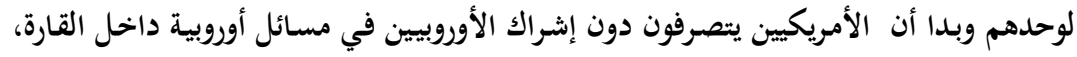

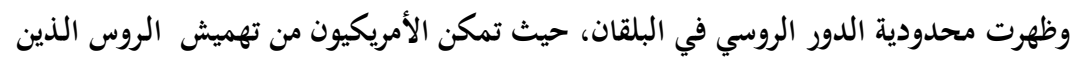

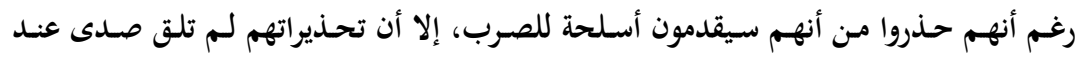

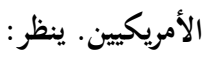
خير الدين العايب: التخوف الأمريكي من المشاريع العسكرية الأوروبية، الموقع الالكتروني

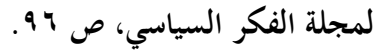

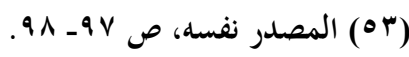

(؛ (0) موسى الزعبي: نهاية الحرب الباردة وإعادة فحص الأمن، الموقع الالكتروني لمجلة الفكر 